University of Nebraska - Lincoln

DigitalCommons@University of Nebraska - Lincoln

\title{
DO HARVEST REFUGES BUFFER KANGAROOS AGAINST EVOLUTIONARY RESPONSES TO SELECTIVE HARVESTING?
}

\author{
Brigitte Tenhumberg \\ University of Nebraska - Lincoln, btenhumberg2@unl.edu \\ Andrew J. Tyre \\ University of Nebraska at Lincoln, atyre2@unl.edu \\ Anthony R. Pople \\ University of Queensland \\ Hugh P. Possingham \\ University of Queensland
}

Follow this and additional works at: https://digitalcommons.unl.edu/bioscifacpub

Part of the Life Sciences Commons

Tenhumberg, Brigitte; Tyre, Andrew J.; Pople, Anthony R.; and Possingham, Hugh P., "DO HARVEST REFUGES BUFFER KANGAROOS AGAINST EVOLUTIONARY RESPONSES TO SELECTIVE HARVESTING?" (2004). Faculty Publications in the Biological Sciences. 97.

https://digitalcommons.unl.edu/bioscifacpub/97

This Article is brought to you for free and open access by the Papers in the Biological Sciences at DigitalCommons@University of Nebraska - Lincoln. It has been accepted for inclusion in Faculty Publications in the Biological Sciences by an authorized administrator of DigitalCommons@University of Nebraska - Lincoln. 


\title{
DO HARVEST REFUGES BUFFER KANGAROOS AGAINST EVOLUTIONARY RESPONSES TO SELECTIVE HARVESTING?
}

\author{
Brigitte Tenhumberg, ${ }^{1,2}$ Andrew J. Tyre, ${ }^{1}$ Anthony R. Pople, And Hugh P. Possingham \\ The Ecology Centre, University of Queensland, St. Lucia, Queensland 4072, Australia
}

\begin{abstract}
There is a wealth of literature documenting a directional change of body size in heavily harvested populations. Most of this work concentrates on aquatic systems, but terrestrial populations are equally at risk. This paper explores the capacity of harvest refuges to counteract potential effects of size-selective harvesting on the allele frequency of populations. We constructed a stochastic, individual-based model parameterized with data on red kangaroos. Because we do not know which part of individual growth would change in the course of natural selection, we explored the effects of two alternative models of individual growth in which alleles affect either the growth rate or the maximum size. The model results show that size-selective harvesting can result in significantly smaller kangaroos for a given age when the entire population is subject to harvesting. In contrast, in scenarios that include dispersal from harvest refuges, the initial allele frequency remains virtually unchanged.
\end{abstract}

Key words: body size; environmental stochasticity; genetic effects; harvest refuge; individualbased model; kangaroo; Macropus rufus; size-selective harvesting.

\section{INTRODUCTION}

Changes in body size in response to selective harvesting are of great interest and there are several models of the underlying mechanisms of this phenomenon. Ratner and Lande (2001) review empirical and theoretical work in this area and summarize the mechanisms proposed to explain observed changes in body size in harvested populations. They identify three categories of possible mechanisms: (1) abiotic factors influencing fish growth and development, e.g., large-scale ocean regime shifts that change water temperature, salinity, or eutrophication; (2) biotic factors, including relaxing density-dependent effects on growth due to changes in the population density; and (3) effect of harvesting on population demography and genetics. Their review concentrates on marine and freshwater organisms, but applies generally to harvested animals.

Among terrestrial animals, "trophy" species, such as the Saiga antelope (Saiga tatarica), elephants, moose, or elk, are selectively harvested because antlers or tusks have a higher value than animal meat. Theoretical work on moose (Alces alces) (Hundertmark et al. 1993) and elk (Cervus elaphus) (Thelen 1991) suggests that selective harvesting of bulls with a minimum antler length can change the frequency of alleles favoring antler growth. There is also empirical evidence for the potential of selective harvesting to influence the distribution of traits. For example, in South Luangwa

Manuscript received 24 November 2003; accepted 25 November 2003; final version received 19 December 2003. Corresponding Editor: W. S. C. Gurney.

${ }^{1}$ Present Address: School of Natural Resources, University of Nebraska-Lincoln, 302 Biochemistry Hall, East Campus, Lincoln, Nebraska 68583-0759 USA.

${ }^{2}$ E-mail: btenhumberg2@unl.edu
National Park in Zambia, the proportion of tuskless elephants (Loxodonta africana) increased from $11 \%$ to $38 \%$ in only 20 years due to ivory poaching (Jachmann et al. 1995).

Changing allele frequencies in terrestrial species has important implications for conservation managers as well. For example, sanctuaries for endangered species are occasionally so successful that managers are forced to control population density through translocations or culling (e.g., Sukumar 1991, Armbruster and Lande 1993, Chapman et al. 1998, Treydte et al. 2001). In this case, potential indirect genetic effects of "harvesting" cannot be ignored.

In Australia there is increasing concern about the possible consequences of selective harvesting of kangaroos (Croft 1999). This paper uses a stochastic simulation model to explore the impact of harvesting on potential genetic controls of growth and survival in kangaroos. The results are directly relevant to the specific issue of kangaroo management. Management strategies can influence harvesting rate, minimum size of the target animal, and the size and location of harvest refuges. We also use the model to make more general comments on the evolutionary impact of size-selective harvesting in a stochastic environment.

Selective harvesting can alter the pattern of age- or size-specific mortality, which also can produce evolutionary change in life history and morphological traits (Miller 1957, Handfort et al. 1977, Ricker 1981, Wohlfarth 1986, Nelson and Soulé 1987, Edley and Law 1988, Law 1991, Policansky 1993, Rijnsdorp 1993, Murphy et al. 1994, Hutchings 1999). Models exploring the evolutionary dynamics of body size under harvesting often make the simplifying assumption that harvesting is the only source of selection on size (Law 
1991, Law and Rowell 1993). Ratner and Lande (2001) criticize these assumptions because most populations experience natural selection with respect to polygenic (quantitative) morphological traits. In their view, "stabilizing viability selection and directional fecundity selection on size traits interact with size-selective harvesting, and models that omit these interactions may produce incomplete or misleading results." Our model therefore includes increased mating success for larger males and reduced survival in drought as other sources of selection on body size.

Theoretical work usually considers harvesting strategies that differ in their degrees of size selectivity, i.e., a range of minimum sizes (Law 1991, Law and Rowell 1993). In fish the minimum size is often determined by the mesh size of the fishing nets, and fish above that size have the same probability of being caught regardless of population density. In terrestrial animals, the size selectivity is more complex. The minimum size is usually dictated by economic factors or regulations, but the probability of harvesting an individual depends on the population density and the individual's size relative to the size of other animals. If the population density is low, it takes harvesters a long time to find an animal; consequently, they harvest it as long as it is above the minimum marketable size. With increasing population density, the encounter rate increases and harvesters become more selective because large animals are often more valuable and there is usually a limit to the number that can be harvested in a single foray (e.g., vehicle size). Such capacity effects also have the potential to affect size selectivity in marine systems (Gillis et al. $1995 a, b)$.

In this paper, one of the primary questions is how dispersal of individuals from a nonharvested area (a refuge) may counteract the genetic impact of size-selective harvesting. There is a growing interest in the role of marine reserves to conserve the genetic viability and identity of marine stock (Trexler and Travis 2000, Conover and Munch 2002). Such systems can be described as source-sink metapopulations, in which the refuge population acts as source and the harvested population as sink. Theoretical work (e.g., Wootton and Bell 1992, Donovan et al. 1995, Dias 1996, Gaona et al. 1998) suggests that metapopulations with at least one source population have a lower probability of extinction. Thus, we can expect that harvest refuges will increase the demographic viability of the kangaroo population. The existence of harvest refuges in the kangaroo system and their potential effect on demographic and genetic viability depend on the spatial variability in harvest and the mobility of kangaroo populations.

The maximum annual rate of kangaroo harvesting is determined by state conservation agencies and is a quota for an entire state. The annual quota varies between $15 \%$ and $20 \%$ of the statewide population estimated with harvest-independent surveys. However, harvesting is usually concentrated in some areas whereas oth- ers are not harvested at all because of differences in accessibility and the location of refrigeration units for carcass storage. This spatial variation in harvesting rates implicitly creates harvest refuges, which may replenish kangaroo abundance in the harvested areas (Pople 1996). It is reasonable to assume that only natural selection influences kangaroo populations in refuge areas.

Whether or not spatial variability in harvest actually improves the demographic and genetic viability of a harvested population depends on the movement rates between harvested and nonharvested areas (Trexler and Travis 2000). If movement rates are too low, the two areas will function as independent populations, and both natural and artificial selection will lead to genetic divergence. If movement rates are too high, the two areas effectively become one, and there also will be no genetic benefit to harvest refuges. Kangaroos, particularly red kangaroos (Macropus rufus), are in general very mobile (Frith 1964, Bailey 1971, Denny 1980, Priddel 1987, Priddel et al. 1988a, $b$, Croft 1991, Norbury et al. 1994). The majority of the population does not move more than $10 \mathrm{~km} /$ year, but some individuals disperse over distances of tens or hundreds of kilometers. Exactly where this places kangaroos on the scale of movement effects on genetics just described is unclear, so in what follows, we explore the sensitivity of our results to a broad range of movement rates.

This paper describes a model of the genetic consequences of selective harvesting on the frequency of genes determining kangaroo body size and survival in droughts. Analytical quantitative genetic models usually assume a normal phenotype distribution, random mating, and constant genetic variance (Lande 1976, Falconer and Mackay 1996, Ratner and Lande 2001). In many biological systems these assumptions are violated. Our model is a stochastic, individual-based simulation model that allows us to consider more complex scenarios that would not be feasible in an analytical model. Comprehensive stochastic computer simulations are increasingly used to test predictions of analytical models (e.g., Bürger 1999, Reeve 2000). The results of the model suggest that size-selective harvesting results in a higher frequency of genotypes with smaller asymptotic size or growth rate, in agreement with other models of size-selective harvesting (e.g., Law 1991, Law and Rowell 1993, Ratner and Lande 2001). If there is dispersal from refuge populations, the initial gene frequency remains virtually unchanged. This model is tailored to red kangaroos, but we believe that the predictions would apply to a variety of other species living in arid environments, such as the African savannah or the Arabian Peninsula.

\section{Model Overview}

In the literature there are numerous attempts to model the population dynamics of kangaroos as a function of rainfall, resource availability, density dependence, and 
environmental stochasticity (see review in Cairns 1989 , McCarthy 1996). Our objective is not to create a complex model of population dynamics as it relates to the environment, but to evaluate the potential for evolutionary change as a result of size-selective harvesting. Thus we ignore interspecific competition (e.g., with sheep) and the interactions of pasture growth and kangaroo performance. Instead, we use rainfall as a surrogate for resource availability. Large kangaroos are gregarious; the only permanent grouping is between a female and her dependent young-at-foot (Jarman and Coulson 1989). Although relatively large groups sometimes form, these groups are unstable in their composition (Croft 1980). In the interests of keeping the model from becoming too complex, we ignore smallscale group structure in our model.

The model includes demographic and environmental stochasticity. Demographic stochasticity means that at any point in time there is a probability that an individual dies or reproduces. The random nature of sex determination of offspring is also included. Environmental stochasticity enters the model through rainfall. Rainfall strongly influences the population dynamics of arid-zone kangaroos through food availability. The population size fluctuates to a great extent as a consequence of including environmental stochasticity in the model.

The model is individual based, and therefore each individual is tracked as a unique and discrete entity. Individual-based modeling is a widely used tool for simulating ecological systems (see review in Grimm 1999, Grimm et al. 1999), especially for models where individual variability is critical for the population dynamics. Our model keeps track of the individual properties of age, size, sex, and genotype. At every time step (= two months), the model cycles over lists of males and females and determines the fate of each individual. The different population processes occur in the following sequence:

1. Rainfall.-At the beginning of each year the annual rainfall is determined by randomly drawing a number from historical rainfall data that have been collected for 123 years at Menindee (near Kinchega National Park) in western New South Wales, Australia. This parameter is treated as an indicator for the availability of resources, such as food and water, for the whole year.

2. Harvesting.- In our model, harvesting starts 100 years after the beginning of a simulation run, to allow the gene frequencies and age distributions to approach equilibrium. At the beginning of each year, the number of kangaroos to be harvested is calculated from the kangaroo density of the previous year and the harvesting quota. Individuals are chosen randomly from male and female lists and are exposed to harvesting. The probability of being shot depends on the size of the chosen kangaroo and overall kangaroo abundance.

3. Mating and reproduction.-Each female without a pouch young mates and gives birth to a pouch young with probability $f$; the sex is assigned randomly with a sex ratio of $1: 1$. The father of the offspring is determined in two steps: first, the female encounters a male chosen randomly from the list of mature males, and second, the probability that this male successfully mates with the female depends on his size relative to all other males. Both successful and unsuccessful males go back to the list and may be selected again. This process is repeated until the female is successfully mated. It is possible that a male can have more than one opportunity to mate with a particular female, and sometimes even very small males will mate successfully. Newborn kangaroos can die at birth; the probability of death increases with increasing kangaroo abundance.

4. Natural mortality, aging, and growing.-At each time step there is a chance that an individual will die. If a female dies, her dependent offspring die with her. The surviving individuals age by one time step and increase in size. Based on its new age, an individual may move up one stage class. For example, at the age of 8 months, pouch young turn into "young-at-foot," and at the age of 12 months, young-at-foot turn into subadults. New subadults are independent of their mother and, depending on their sex, they are added to female or male lists. Whether female subadults reach maturity depends not only on age, but also on their size and the amount of rainfall.

5. Dispersal.-At every time step some individuals move between harvested and nonharvested populations. Dispersing individuals from the refuge population replace harvested individuals to some extent and increase the genetic variability of the harvested population.

Note that processes (1) and (2) occur only every sixth time step.

\section{Model Assumptions}

We use the following notational conventions in what follows: $i$ and $j$ index individuals in a population, and $i$ usually refers to a "focal" individual, whereas $j$ is used in summations over entire populations; $y$ is size, $z$ is sex, and $x$ is age in time steps; $\mu$ is a probability of dying during a time step; $p$ is always a probability of an event occurring during a single time step, and the subscript identifies the event. All model parameters are listed in Table 1, and the estimation of the parameters is described in Appendix A.

\section{Sex ratio}

In large, sexually dimorphic, polygynous mammals such as kangaroos, the variance in the reproductive success of males is greater than in females. Current theory suggests that in these animals, a mother that is in good condition should preferentially conceive sons and provide them with above-average parental care, and a mother that is in poor condition should preferentially conceive daughters and provide them with below-average parental care (Trivers and Willard 1972, 
TABLE 1. Base value of model parameters, and the probability distribution functions (PDF) used in the sensitivity analysis.

\begin{tabular}{|c|c|c|c|c|}
\hline \multicolumn{2}{|l|}{ Parameter } & \multirow[b]{2}{*}{ Conditions } & \multirow[b]{2}{*}{ Base value } & \multirow[b]{2}{*}{ PDF $\ddagger$} \\
\hline Description & Symbol $\dagger$ & & & \\
\hline \multicolumn{5}{|l|}{ Maturity } \\
\hline Intercept & $w_{0}(3)$ & & 1.137 & normal $(1.137,5)$ \\
\hline Weight & $w_{1}(3)$ & & 0.653 & normal $(0.653,0.14)$ \\
\hline Age & $w_{2}(3)$ & & -8.298 & normal $(-8.298,3.4)$ \\
\hline Rain & $w_{3}(3)$ & & -0.046 & normal $(-0.046,0.016)$ \\
\hline Age : rain & $w_{2,3}(3)$ & & 0.033 & normal $(0.033,0.01)$ \\
\hline Male bias in birth & $\alpha$ & & 0.5 & beta $(12,5)$ \\
\hline Male dominance & $v(4)$ & & 5 & gamma $(5,1)$ \\
\hline Birth rate & $f$ & & 0.95 & beta $(40,2)$ \\
\hline \multicolumn{5}{|l|}{ Dispersal } \\
\hline $\begin{array}{l}\text { From harvested to non- } \\
\text { harvested }\end{array}$ & $\varepsilon_{\mathrm{H} \rightarrow \mathrm{NH}}(13)$ & & 0.001 & gamma $(2,400)$ \\
\hline $\begin{array}{l}\text { From nonharvested to } \\
\text { harvested }\end{array}$ & $\varepsilon_{\mathrm{NH} \rightarrow \mathrm{H}}(14)$ & & 0.001 & gamma $(3.5,150)$ \\
\hline Male bias & $\theta$ & & 0.6 & beta $(6,4)$ \\
\hline \multicolumn{5}{|l|}{ Mortality } \\
\hline Age & $\rho(5)$ & age $<x^{*}$ & $0.05 \S$ & gamma $(60,1600)$ \\
\hline & & age $\geq x^{*}$ & $0.05 \S$ & gamma $(60,1600)$ \\
\hline & $\kappa(5)$ & age $<x^{*}$ & $0.3 \S$ & gamma $(10,33)$ \\
\hline & & age $\geq x^{*}$ & $10 \S$ & normal $(10,1)$ \\
\hline & $x^{*}$ & & 14 & normal $(14,1.5)$ \\
\hline Rainfall & $\mu_{0}(8)$ & males & 0.5 & beta $(12,12)$ \\
\hline & & females & 0.55 & beta $(14.5,12)$ \\
\hline & & young & 0.2 & beta $(2,14)$ \\
\hline & $b(7)$ & males & 0.01 & gamma $(10,1000)$ \\
\hline & & females & 0.01 & gamma $(10,1000)$ \\
\hline & & young & 0.014 & gamma $(20,1430)$ \\
\hline Density dependence & $\omega(9)$ & young only & 0.001 & beta $(4,3000)$ \\
\hline Genes & $m(\mathrm{C} 1) \|$ & & 0.085 & gamma $(4,47)$ \\
\hline & $d(\mathrm{C} 1) \|$ & & 0.009 & gamma $(4,444)$ \\
\hline \multicolumn{5}{|l|}{ Growth } \\
\hline Age & $y_{\infty}(10)$ & males & 190 & normal $(190,10)$ \\
\hline & & females & 160 & normal $(160,10)$ \\
\hline & $c(10)$ & males & 0.25 & beta $(20,60)$ \\
\hline & & females & 0.47 & beta $(45,50)$ \\
\hline & $x_{0}(10)$ & males & -3.4 & normal $(-3.4,0.3)$ \\
\hline & & females & -2 & normal $(-2,0.3)$ \\
\hline Rainfall & $g(12)$ & & 1.2 & gamma $(20,17)$ \\
\hline & $h(12)$ & & 0.015 & gamma $(10,666)$ \\
\hline Genes & $\sigma_{\text {growth, } 1}$ & genes $\rightarrow y_{\infty}$ & & normal $(8,1.5)$ \\
\hline & $\sigma_{\text {growth, 2 }}$ & genes $\rightarrow c$ & 0.05 & normal $(0.05,0.01)$ \\
\hline \multirow{2}{*}{$\begin{array}{l}\text { Harvesting } \\
\quad \text { Mortality rate }\end{array}$} & $k(1)$ & & 0.0001 & normal $(0.0001,0.00003)$ \\
\hline & $\begin{array}{l}\mu_{\text {harvest }} \\
\phi(1)\end{array}$ & & 0.5 & normal $(0.5,0.2)$ \\
\hline Minimum size & $y_{\min }$ & & $142 \mathrm{~mm}(\approx 25 \mathrm{~kg})$ & normal $(25,5)$ \\
\hline Quota & $q$ & & 0.15 & normal $(0.15,0.03)$ \\
\hline
\end{tabular}

$\dagger$ Numbers in parentheses indicate the equation in which the parameter is used.

$\$$ Numbers in parentheses are the parameters of the PDF used in the sensitivity analysis.

$\S$ Parameters that were varied independently for both sexes in the sensitivity analysis.

$\|$ Eq. C. 1 in Appendix C.

Maynard Smith 1980). In the empirical literature, there is mixed support for this theory. Some researchers found that the sex ratio of newborns varies with environmental conditions (kangaroos; Johnson and Jarman [1983]), maternal age, social rank, and body condition (red deer; Clutton-Brock et al. [1982]; rednecked wallabies Macropus rufogriseus and eastern grey kangaroos M. giganteus; Stuart-Dick and Higginbottom [1989]). In contrast, in an extensive study over three years on red kangaroos M. rufus ( $n>2000)$, Pople (1996) detected little sex bias in pouch young and no relationship between pouch young sex and maternal age or condition.

For reasons of parsimony, we assume in our model that environment and size do not affect the sex ratio. It is unlikely that variation in the sex ratio would change the model predictions notably because under size-selective harvesting, the largest individuals of 
each sex are killed, resulting in natural selection favoring smaller individuals.

\section{Harvesting}

In the model we assume that a given proportion, $q$, of the kangaroo population is harvested each year. Based on $q$ and the kangaroo abundance, $n$, the number of harvested individuals (= target) is calculated and individuals are removed randomly at the beginning of each year. In the model we assume the following scenario: If a shooter encounters a group of animals (s)he usually shoots the largest one first and the other animals in the group escape. Group size is bigger when kangaroo abundance is larger, and at very low density, only solitary animals are encountered. Therefore, the probability of a kangaroo surviving harvest, $1-\mu_{\text {harvest }}$, depends on its size relative to the size of the other kangaroos, and kangaroo abundance, and is calculated as follows:

$$
\mu_{\text {harvest }, i}= \begin{cases}0 & \text { if } y_{i}<y_{\min } \\ \phi \frac{y_{i}^{k n^{2}}}{\sum_{j} y_{j}^{k n^{2}}} & \text { if } y_{i} \geq y_{\min }\end{cases}
$$

where $y_{i}$ is the size of kangaroo $i, \phi$ is a scaling constant to adjust for different harvesting pressure, $n$ is the abundance of adult and subadult kangaroos, and $k$ is an index determining how size-selective harvesters are. With increasing $n$, the selectivity for bigger animals increases, and if $k n^{2}$ is close to 0, all animals above the minimum size, $y_{\min }$, have an equal probability of being shot. We use $n^{2}$ rather than $n$ to increase the effect of abundance on $\mu_{\text {harvest }}$.

To determine which animal is harvested and removed from the population, we randomly choose males and females from the population. Chosen individuals are "shot" with the probability $\mu_{\text {harvest }}$, and are removed from the population. If a female is shot, all of her dependent young die with her. However, the young are not counted toward the harvesting target. Surviving individuals remain in the population. Individuals can be chosen more than once and there is a chance that relatively small individuals will be harvested. The random selection process continues until the target quota proportion $q$ of the current population has been harvested.

\section{Reproduction}

In the model, the probability that a female will reach maturity, $p_{\text {mature }}$ depends on her age $(x)$, size $(y)$, and the current rainfall $(R)$, and is given by

$$
\begin{aligned}
p_{\text {mature }}(y, x, R) & =\frac{e^{\mathrm{lp}}}{1+e^{\mathrm{lp}}} \\
\mathrm{lp} & =w_{0}+y_{i} w_{1}+x w_{2}+R w_{3}+x R w_{2,3}
\end{aligned}
$$

where $1 p$ is the linear predictor.

We have no data to estimate the probability of maturation for males. Therefore, we assume that males randomly mature between 2.5 and 3.5 years. For males, the timing of maturity has only a small influence on fitness because males less than 4 years old are relatively small in size compared to the rest of the male population and, consequently, have a very low probability of mating.

The probability that male $i$ will mate successfully after encountering a female, $p_{\text {mating }}(y, v)$, is given by

$$
p_{\text {mating }}(y, v)=\frac{y_{i}^{v}}{\sum_{j} y_{j}^{v}}, \quad v \geq 0
$$

where $y_{\mathrm{i}}$ is the size of kangaroo $i$, and the summation is over all mature males, and $v$ determines how much the relative size of individual $i$ influences mating success. For $v>1$, the influence is large; for $0<v<1$, the influence is small; and for $v=0$, the mating success is independent of size.

\section{Mortality}

The natural mortality depends on age, sex, and rainfall (Frith and Sharman 1964, Newsome 1965, Bayliss 1985, Shepherd 1987, Pople 1996). For very young animals, there is an additional independent mortality event, the probability of which is a function of total population abundance. Independence means that surviving one phase does not alter the probability of dying in a later phase. The mortality probability that we calculate, $\bar{\mu}_{R, x, z}$, where $R$ is the annual rainfall for the current year, $x$ is the age of the individual, and $z$ is the sex, is the average across the genetic variation in the population; the mortality probability for a particular individual also incorporates the effect of its genome (see Genetics).

We use a Weibull function (McCallum 2000) to include the effect of age on the instantaneous death rate. The age-specific death rate at age $x$, also known as the hazard function in the survival literature, is

$$
\kappa \rho(\rho x)^{\kappa-1}
$$

where $\rho$ is the rate and $\kappa$ is the shape parameter. If $\kappa$ $>1$, the death rate increases with age; if $\kappa<1$, the death rate decreases with age. When $\kappa=1$, the death rate is a constant and the distribution of survival times reduces to the exponential distribution. By changing $\kappa$ for first part of the age range, we can let the instantaneous death rate decrease with age as a result of increasing experience (e.g., habitat selection), and during the last part of the age range, we can let the instantaneous death rate increase as a result of senescence, where $x^{*}$ is the age in years at which senescence starts affecting survival.

The model uses discrete time steps, so we calculate the probability of dying from age $x$ to $x+1$ when rainfall is not limiting (i.e., $R=\infty$ ), $\bar{\mu}_{\infty, x, z}$, from Eq. 5: 


$$
\begin{aligned}
\bar{\mu}_{\infty, x, z} & =1-\exp \left[-\int_{x}^{x+1} \kappa \rho(\rho u)^{\kappa-1} d u\right] \\
& =1-e^{(\rho x)^{\kappa}-[\rho(x+1)]^{\kappa}} .
\end{aligned}
$$

where $u$ is a temporary integration variable.

In general, the survival probability of females is higher than that of males, and the survival probability of pouch young and young-at-foot is lower than that of adults. Survival in juveniles is lowest in late pouch life and among young-at-foot (Frith and Sharman 1964, Newsome 1965, Shepherd 1987, Pople 1996). In the model, we therefore assume that, given the mother stays alive, young only die of natural causes at 5-12 months of age (i.e., $\bar{\mu}_{R, x, z}=0$ for $x<5$ months). This limits females to attempting to rear a maximum of three offspring each year.

We assume that rainfall causes mortality to decrease from an upper limit $\left(\bar{\mu}_{0, x, z}\right)$ to a lower limit when rainfall is not limiting (Eq. $6 ; \bar{\mu}_{\infty, x, z}$ ) along a logistic curve (McCallum 1995):

$$
1-\mu_{R, x, z}=\left(1-\mu_{\infty, x, z}\right)\left(\frac{e^{a_{x, z}+R b_{x, z}}}{1+e^{a_{x, z}+R b_{x, z}}}\right)
$$

or

$$
\mu_{R, x, z}=\frac{1+\mu_{\infty, x, z} e^{a_{x}+R b_{x}}}{1+e^{a_{x}+R b_{x}}}
$$

where $b_{x, z}$ determines the slope (the estimation of this parameter is described in Appendix A), and $a_{x, z}$ is related to the maximum mortality $\left(\mu_{0, x, z}\right)$ by the following relationship:

$$
a_{x, z}=\ln \left(\frac{\mu_{0, x, z}-1}{\mu_{\infty, x, z}-\mu_{0, x, z}}\right) .
$$

This means that, in years of high rainfall, kangaroos experience the lowest mortality $\left(\mu_{\infty, x, z}\right)$ probability for a given age and sex, but with decreasing annual rainfall, the mortality increases to $\mu_{0, x, z}$. How much the mortality increases depends on the degree of drought resistance (see Genetics and Appendix B).

Pouch young and young-at-foot experience a second independent mortality event, the density-dependent phase, in which mortality rates depend on the abundance of the kangaroo population. In our model, the densitydependent mortality of juveniles, $\mu_{n}$, increases exponentially with kangaroo abundance, $n$, at rate $\omega$ :

$$
\mu_{n}=1-e^{-\omega n}
$$

\section{Growth}

In our model we used head length as a surrogate of kangaroo size. We used head length rather than mass because head length cannot decrease as a result of unfavorable environmental conditions. Head length also continues to increase well after maturity and to a greater extent than limb measurements such as pes length (Ealey 1967). We modeled growth of head length with the von Bertalanffy equation (Koojiman 1993):

$$
y_{x}=y_{\infty}\left[1-e^{-c\left(x-x_{0}\right)}\right]
$$

where $y_{x}$ is the head length of an individual at age $x$, $y_{\infty}$ is the asymptotic head length, $c$ is a growth rate, and $x_{0}$ is a shift parameter to allow head length at age 0 to be greater than zero. It is straightforward to rearrange Eq. 10 into a form that estimates the increment of growth over a single time step starting from size $y_{t}$ (McCallum 1995):

$$
\Delta y=\left(y_{\infty}-y_{t}\right)\left(1-e^{-c}\right) .
$$

Growth is also influenced by rainfall, $R$, and the growth increment is reduced by a fraction:

$$
\Delta y_{R}=\Delta y\left(1-g e^{-h R}\right)
$$

where $g$ and $h$ are parameters determining the shape of the exponential curve. Under good conditions, individual growth follows the von Bertalanffy growth equation $\left(\Delta y_{R} \rightarrow \Delta y\right)$, but with decreasing rainfall, the growth slows down and reaches zero in severe droughts $\left(\Delta y_{R} \rightarrow 0\right)$. For a small number of the extreme parameter combinations in the sensitivity analysis, Eq. 12 leads to small negative growth increments under the most severe drought conditions used in the model (annual rainfall $<55 \mathrm{~mm},<1 \%$ of years). In these circumstances, the growth increment was rounded to zero.

\section{Dispersal}

Refuge and harvested populations undergo the same population processes and are affected by the same environmental conditions (i.e., rainfall). At every time step, individuals disperse from the refuge population $(\mathrm{NH})$ to the harvested population $(\mathrm{H})$ and vice versa. We assume that this movement is determined by: (1) the basic dispersal rate, $\varepsilon_{\mathrm{H} \rightarrow \mathrm{NH}}$, or $\varepsilon_{\mathrm{NH} \rightarrow \mathrm{H}}$, (2) the proportion of males among migrants, $\theta$, and (3) the ratio of the kangaroo numbers in both populations. Therefore the individual dispersal rate for males is

$$
\varepsilon_{1}=\theta \varepsilon_{\mathrm{H} \rightarrow \mathrm{NH}} \frac{N_{\mathrm{H}}}{N_{\mathrm{NH}}} \quad \varepsilon_{2}=\theta \varepsilon_{\mathrm{NH} \rightarrow \mathrm{H}} \frac{N_{\mathrm{NH}}}{N_{\mathrm{H}}}
$$

and for females it is

$$
\begin{aligned}
& \varepsilon_{1}=(1-\theta) \varepsilon_{\mathrm{H} \rightarrow \mathrm{NH}} \frac{N_{\mathrm{H}}}{N_{\mathrm{NH}}} \\
& \varepsilon_{2}=(1-\theta) \varepsilon_{\mathrm{NH} \rightarrow \mathrm{H}} \frac{N_{\mathrm{NH}}}{N_{\mathrm{H}}}
\end{aligned}
$$

where $N_{\mathrm{H}}$ and $N_{\mathrm{NH}}$ are the number of kangaroos in the harvested population and refuge population, respectively. The dispersal rate for any particular sex or direction, $\varepsilon$, is converted to the probability that an individual will disperse in a single time step, $p$ (dispersal) using the following equation: 


$$
p(\text { dispersal })=1-e^{-\varepsilon} .
$$

Because $p$ (dispersal) depends on the ratio of the kangaroo numbers in both populations, the smaller population acts as a sink and the larger population as a source until both populations are equal in size. This mechanism is consistent with the concept of an ideal free distribution, in which foragers redistribute themselves so that the resource exploitation rate is the same for all animals (Fretwell and Lucas 1970). The rate $\varepsilon$ is kept small to reduce the likelihood of time-delayed fluctuations in population size.

In real kangaroo populations, movement between harvested and refuge areas is likely to be influenced by differences in habitat quality. Harvesting often concentrates in open, more easily accessible areas, which seem to be more favorable for red kangaroos compared to refuge areas. In the model, we can account for a dispersal preference by using different values for $\varepsilon_{\mathrm{H} \rightarrow \mathrm{NH}}$ and $\varepsilon_{\mathrm{NH} \rightarrow \mathrm{H}}$ in Eqs. 13 and 14.

\section{Genetics}

In life history theory, it is usually assumed that growth is a trade-off with survival, such that the cost of being large is a reduced survival probability (Roff 1992, Stearns 1992). In the absence of such trade-offs, there would be a tendency for fixation at the highest possible trait values. Kangaroo surveys over many years suggest that, in drought years, large individuals are more likely to die than smaller ones. Furthermore, reproductive success is positively correlated with size: size influences mating success in males, whereas size effects initiation of maturity in females. Hence, it appears that there is a trade-off between size and drought resistance in kangaroos, but as far as we know, details on the underlying genetics of this trade-off are unknown. Our goal was to examine the ability of dispersal from nonharvested populations to buffer this trade-off against selection pressure imposed by size-selective harvesting. We employed simulation-based quantitative genetic modeling to generate a range of possible evolutionary responses to harvesting.

We assume that drought resistance and size are additive, quantitative traits. The genome is diploid, with characters being modeled by 20 diallelic autosomal loci with free recombination among them. All of the loci are pleiotropic; at every locus, the allele increasing growth also decreases drought resistance, so that there is always a complete trade-off between the characters (genetic correlation of negative one). Each parent contributes $50 \%$ to the genes of their offspring, chosen at random from the alleles at each locus. Thus, if an individual homozygous for drought resistance (i.e., all drought resistance alleles) mates with an individual homozygous for size alleles, the resulting offspring will have half dought resistance alleles and half size alleles.

There is no dominance between alleles; trait expression depends entirely on the number of alleles for each trait that an individual possesses. Thus, the degree of drought resistance depends on the total number of drought resistance alleles in the whole genome, whereas the growth rate depends on the total number of "size" alleles. Higher or lower numbers of alleles are mapped to trait values using an inverse normal distribution. Genotypes of the population at the beginning of the simulation were sampled independently among loci such that the expected allele frequency at each locus was 0.5. Model runs based on 100 loci for each trait resulted in the same equilibrium allele frequency as runs using 20 loci, but it took longer to reach the equilibrium. Therefore, we have limited our analyses to 20 loci for the sake of simplicity.

Size genes.-In our model there are two benefits of increased growth rate. First, male size is correlated with mating success (Walker 1995). If two or more males compete for access to a female, the largest one usually wins. This does not mean that small individuals are excluded from mating, but their probability of mating successfully is reduced compared to that of larger counterparts. Second, age at maturity depends on size. Larger females tend to reach maturity earlier than smaller individuals. In the model the genetic make up of an individual determines size at birth and the age at which individuals reach the sex-specific asymptotic size.

Size genes could influence growth in different ways. In this model we consider two different mechanisms. First, we assume that the entire growth curve is shifted up or down depending on the frequency of size genes. This means that an individual with a small number of size genes starts out small and never catches up in size relative to an individual with many size genes. Second, we assume that the number of size genes determines the growth rate, $c$, in Eq. 10. Following this latter assumption, individuals approach the same asymptotic head size at different rates. The number of size genes is mapped to asymptotic size, $y_{\infty}$, or growth rate, $c$, associated with a particular number of size genes using an inverse Gaussian function with mean $\bar{y}_{\infty}$, or $\bar{c}$, and standard deviation, $\sigma_{\text {growth. }}$. The exact value for an individual depends on the number of size alleles $(S)$ that they have relative to the maximum possible $\left(S_{\max }\right)$,

$$
y_{\infty}=\bar{y}_{\infty}+\sigma_{\text {growth }} \Phi^{-1}\left(S / S_{\max }\right)
$$

where $\Phi^{-1}$ is the inverse normal distribution function. Using the baseline parameters, the effect of the different number of size genes causes the asymptotic male head size to vary between $168 \mathrm{~mm}$ (no size alleles) and $201 \mathrm{~mm}(100 \%$ size alleles) in the first growth model. Under the second growth model, male kangaroos reach $170 \mathrm{~mm}$ head size between 3 and 12 years of age (100\% and $0 \%$ size alleles, respectively).

Drought resistance genes.-Annual rainfall greatly influences water availability and plant growth and, consequently, kangaroo mortality (Bayliss 1985). Therefore, in this paper we use drought resistance as being analogous to stress tolerance caused by poor nutrition 
TABLE 2. Starting conditions of all simulations.

\begin{tabular}{llll}
\hline \hline \multicolumn{1}{c}{ Parameter } & Term & Value & \multicolumn{1}{c}{ PDF $\dagger$} \\
\hline Number of males & $n_{\text {males }}$ & 50 & constant \\
Number of females & $n_{\text {females }}$ & 50 & constant \\
Proportion of size alleles & $\gamma$ & 0.5 & Beta $(5,5)$ \\
\hline
\end{tabular}

$\dagger$ Probability distribution function for the sensitivity analysis.

and dehydration. The number of "drought resistance" alleles results in a particular survival rate in exactly the same manner as for growth effects (see Eq. 16), but with mean $\bar{\mu}_{R, x, z}$ (see Eq. 7), and standard deviation $\sigma_{\text {drought }}$. We model the increasing influence of drought resistance allele with decreasing rainfall by increasing $\sigma_{\text {drought }}$ as rainfall decreases. Therefore, in a run of "good" years there is no advantage to having drought resistance alleles, because the survival of all individuals of the same sex and age is virtually the same. See Appendix $\mathrm{C}$ for a more detailed description of how $\sigma_{\text {drought }}$ influences survival.

\section{Sensitivity analysis}

Our model is very complex and there is considerable uncertainty in estimates of the input parameters. We want to know how changes in the input parameters would alter the model predictions. Sometimes the effect of changing one parameter value depends on the values of other parameters. The technique that we used is called Latin Hypercube Sampling (LHS) and is described in Appendix D. It has been used in the analysis of complex ecological models elsewhere (Rushton et al. 2000a, b). We consider four scenarios within which the parameters are varied: (1) size alleles determine asymptotic growth, no dispersal from nonharvested population; (2) size alleles determine growth rate, no dispersal from nonharvested population; (3) size alleles determine asymptotic growth, dispersal from nonharvested population; or (4) size alleles determine growth rate, dispersal from nonharvested population.

We also varied the initial proportion of size genes in the population (Table 2). We keep track of genetic changes by examining the number of size alleles as a proportion of its maximum $(S)$. For example, $S=0.6$ means that kangaroos have, on average, $60 \%$ size alleles and $40 \%$ drought resistance alleles. To allow the allele frequency to stabilize in the absence of harvesting, the populations were not harvested in the first 100 years. We calculated $S$ in the year before harvesting commences $\left(S_{1}\right)$ and after 100 years of harvesting $\left(S_{2}\right)$, and used the difference in $S\left(\Delta S=S_{2}-S_{1}\right)$ as an indicator for the magnitude of genetic change. A negative value of $\Delta S$ indicates that kangaroos grow more slowly or have a lower asymptotic size. We also present results for the effect of harvesting on abundance in the harvested population, calculated as the difference between the population size at the onset of harvesting $\left(n_{1}\right)$ and abundance after 100 years of harvesting $\left(n_{2}\right)$, $\Delta n=n_{2}-n_{1}$.
The relationship between variation in the input parameters and the magnitude of genetic change is quantified with Partial Rank Correlation Coefficients (PRCC; Blower and Dowlatibadi 1994). Although we calculated PRCCs for all combinations of inputs and outputs, for the sake of brevity we present only the values for the combinations that we are most interested in: the effect of management controls and dispersal rates. We plot the relationship between inputs and $\Delta S$ or $\Delta n$ only for combinations with correlations significant at $P<0.01$. Note that the graphs do show the median genetic or abundance change for all parameter combinations; we simply are not presenting them as functions of inputs with weak relationships or that are beyond the control of managers.

\section{Heritability estimates}

The magnitude of a genetic response to selection depends on the amount of additive genetic variation that contributes to the overall phenotypic variation observed and the heritability of that additive genetic variation. Therefore we calculated the heritability of the rate of growth to maturity (calculated as size at maturity/age at maturity), using all females maturing between year 50 and year 100 in a single baseline run, a total of 3926 individuals. We calculated an offspringmidparent regression (Hartl and Clark 1989), which is the phenotypic covariance between the average growth rate to maturity of the two parents and the growth rate to maturity of their offspring, divided by the phenotypic variance of growth rate to maturity. We then calculated a bootstrap standard error for this estimate using 1000 bootstrap replicates.

\section{RESULTS}

The population dynamics of the simulated kangaroo populations are strongly influenced by annual rainfall. In years of high rainfall, the population size increases; in drought years, the numbers sharply decrease (Fig. $1)$. This pattern is consistent with that observed in natural populations (Caughley et al. 1984, Bayliss 1985, 1987, Cairns and Grigg 1993). Harvesting reduces simulated kangaroo abundance, and kangaroo numbers fluctuate around a lower mean value.

Despite the large fluctuation in population numbers, the average allele frequency across loci is quite stable prior to the onset of harvesting (Fig. 2). However, with no dispersal between populations and the highest minimum size for harvesting $\left(y_{\min }\right)$, the proportion of size alleles decreases markedly in the harvested population 


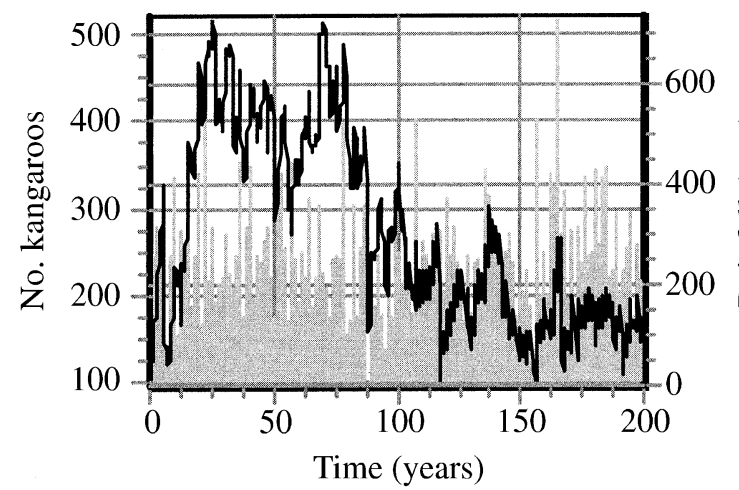

FIG. 1. Simulated population dynamics of red kangaroos (solid line) and the corresponding rainfall (gray bars). Harvesting commences after 100 years, size alleles determine asymptotic growth, and there is no dispersal from the nonharvested population.

after harvesting commences, whereas the proportion of size alleles in the refuge population remains unchanged (Fig. 2). A reduction in the proportion of size alleles $(\Delta S<0)$ means that size-selective harvesting reduces the average age-specific size of kangaroos. This result is consistent with data on heavily harvested populations of several different aquatic species (see review in Ratner and Lande 2001). As a result of the particular tradeoff chosen in our model, size-selective harvesting also increases the degree of drought resistance (or stress tolerance). In the scenarios with dispersal between the refuge population and the harvested population, the median proportion of size alleles remains at about the pre-harvesting level in both populations $(\Delta S \approx 0)$. In the majority of runs, the change in allele frequency due to harvesting does not disappear after the cessation of harvesting.

We used the sensitivity analysis to evaluate (1) how sensitive the model predictions are to the uncertainty in the parameter estimates, and (2) the ability of management controls to counteract the effect of size-selective harvesting. Kangaroo managers can manipulate the harvesting rate, $q$, the size distribution of harvested animals (i.e., $y_{\min }$ ), and they can set aside harvest refuges. In scenarios with no dispersal from harvest refuges, 100 years of size-selective harvesting resulted in a reduced proportion of size genes (median $\Delta S<0$ ) in $85 \%$ of the runs, with $37 \%$ decreasing by -0.1 or more (Fig. 3A, B). The largest change was -0.35 . The partial rank correlation coefficients (PRCCs; Table 3) indicate that the proportion of size alleles decreases with increasing harvesting rate $(q)$ and increasing minimum size $\left(y_{\min }\right)$ for both growth models (PRCCs $<0$ ). Increasing the harvesting rate has a relatively larger effect than increasing the minimum size (see also Fig. 3A, B).

In contrast, in the scenarios with dispersal from harvest refuges, only $54 \%$ of runs had a reduced proportion of size alleles, with only $2 \%$ of runs with a reduction greater than -0.1 (Fig. 3). The largest reduction was -0.19 . The dispersal rate from the harvesting population into the refuge population, $\varepsilon_{\mathrm{H} \rightarrow \mathrm{NH}}$, has a small negative effect on the reduction of size genes (Table 3; Fig. 3C) when size alleles influence the asymptotic size. The minimum harvested size $\left(y_{\min }\right)$ also has a significant negative effect on the median change in both growth models (Table 3), but the magnitude is considerably smaller than that observed when there is no dispersal (Fig. 3D).

The effect of harvesting on the change in abundance is very consistent between growth models and the presence of harvest refuges. Increasing the harvest quota results in a greater decrease in abundance in all scenarios (Fig. 4A,C, Table 3). Increasing the minimum harvested size $\left(y_{\min }\right)$ reduces the change in abundance in all scenarios (Fig. 4B,D, Table 3). The effect of harvesting on abundance is not greatly affected by the presence of harvest refuges; the median change in abundance is -102 without harvest refuges and -89 with refuges.

The heritability of growth rate to maturity for females in the model is 0.14 (bootstrap SE 0.008).

\section{Discussion}

It is believed that refuges help to preserve genetic diversity and to maintain population size and age structure, which are thought to permit evolutionarily adaptive responses in the face of environmental uncertainty (Carr and Reed 1993, Quinn et al. 1993). This paper assesses the value of refuges to prevent evolutionary change due to size-selective harvesting. Our model suggests that it is likely that size-selective harvesting reduces the proportion of size alleles when the entire population is subject to harvesting. Moderate dispersal from nonharvested areas has the potential to counteract this directional change toward smaller kangaroo sizes. These results are not an artifact of random genetic drift

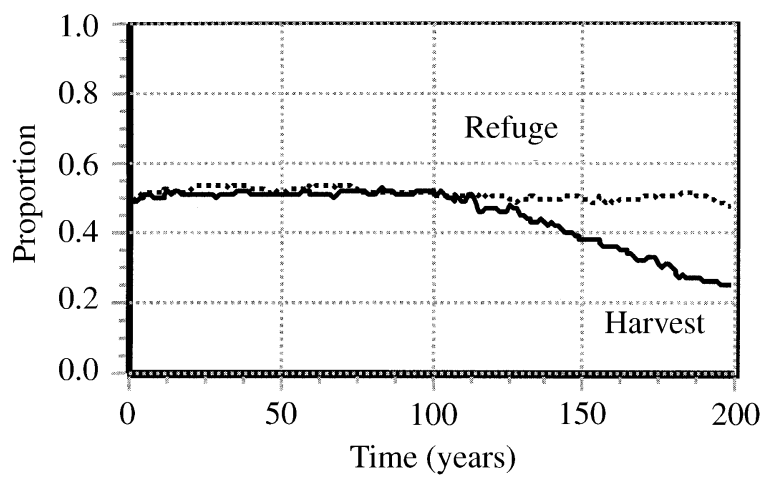

FIG. 2. Average number of size alleles as a proportion of the maximum number for the harvested (solid line) and the nonharvested population (dotted line) when harvesting is maximally size selective. Harvesting commences after 100 simulated years, with minimum size $y_{\min }=35 \mathrm{~kg}$, size alleles determine asymptotic growth, and there is no dispersal between populations. 

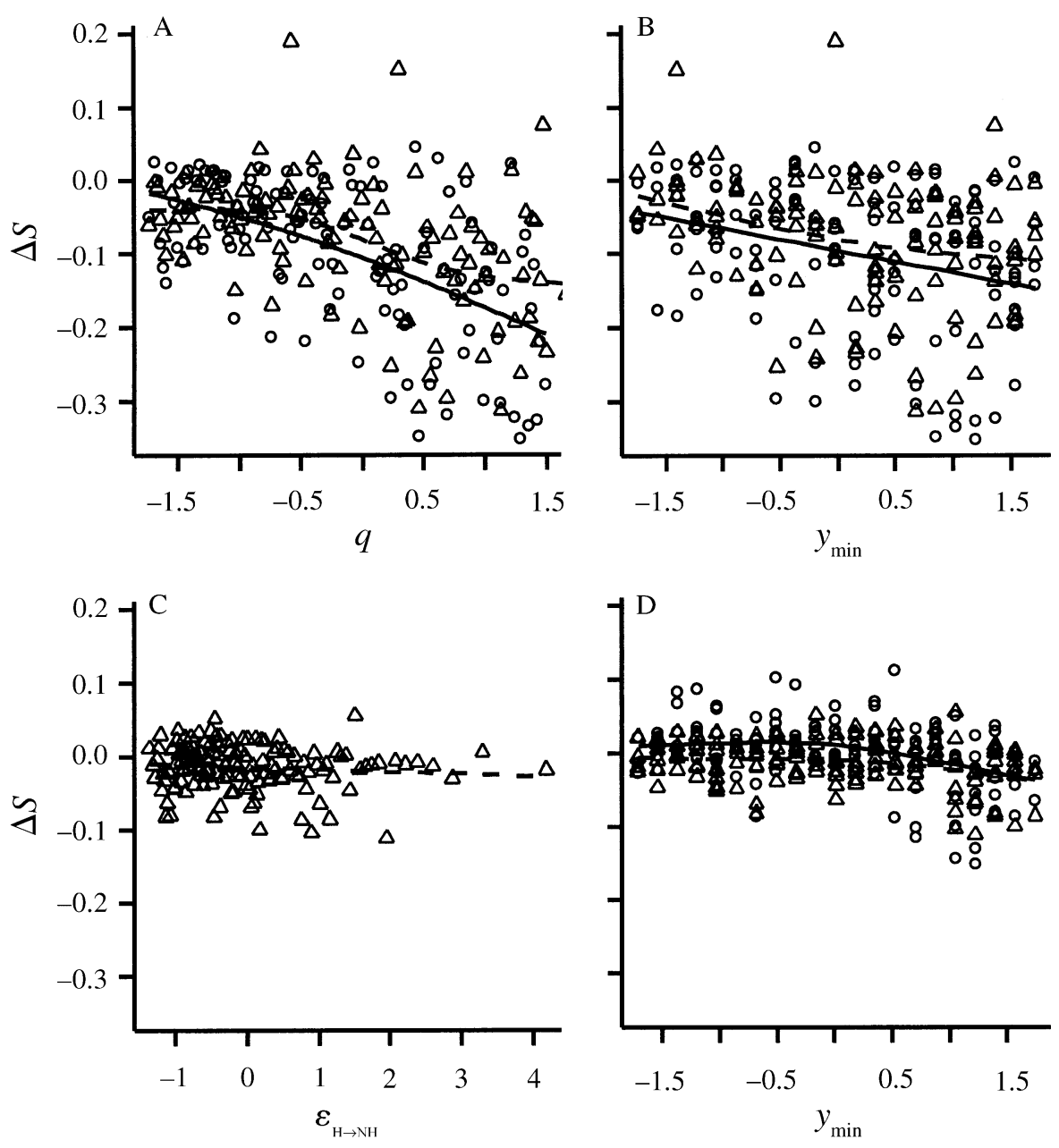

FIG. 3. Influence of size-selective harvesting on the frequency distribution of size alleles of the scenarios with no dispersal (A, B) and with dispersal from harvest refuges (C, D). Each symbol is the median of the 20 replicate runs at a single parameter set; all 150 parameter sets are shown in each panel. Open circles (solid lines) indicate the runs where the size alleles determine the growth rate, $c$, and the open triangles (dashed lines) indicate those runs where the size alleles determine the asymptotic size, $y_{\infty}$. The lines are created using a smooth spline function. Variation around the line is due to variation in the parameters other than the one displayed. $\Delta S$ specifies the change in the proportion of size alleles after 100 years of harvesting; there is no change if $\Delta S=0$. Parameter values for harvesting rate $(q)$, the minimum size $\left(y_{\min }\right)$, and the dispersal rate from the harvested population into the nonharvested population $\left(\varepsilon_{\mathrm{H} \rightarrow \mathrm{NH}}\right)$ are expressed as standard deviations above or below the mean ( 0 indicates the mean parameter value).

TABLE 3. Partial rank correlation coefficients (PRCC).

\begin{tabular}{|c|c|c|c|c|c|}
\hline \multirow[b]{2}{*}{ Parameter } & \multirow{2}{*}{$\begin{array}{c}\text { Size } \\
\text { alleles } \rightarrow\end{array}$} & \multicolumn{2}{|c|}{ No dispersal } & \multicolumn{2}{|c|}{ With dispersal } \\
\hline & & $\Delta S$ & $\Delta n$ & $\Delta S$ & $\Delta n$ \\
\hline \multirow{2}{*}{$q$} & $c$ & -0.58 & -0.23 & -0.16 & -0.36 \\
\hline & $y_{\infty}$ & -0.49 & -0.25 & -0.02 & -0.42 \\
\hline \multirow[t]{2}{*}{$y_{\min }$} & $c$ & -0.32 & 0.36 & -0.32 & 0.26 \\
\hline & $\boldsymbol{y}_{\infty}$ & -0.32 & 0.36 & -0.29 & 0.24 \\
\hline \multirow{2}{*}{$\varepsilon_{\mathrm{H} \rightarrow \mathrm{NH}}$} & $c$ & & & -0.14 & -0.02 \\
\hline & $\boldsymbol{y}_{\infty}$ & & & $-\mathbf{0 . 3 3}$ & 0.05 \\
\hline \multirow[t]{2}{*}{$\varepsilon_{\mathrm{NH} \rightarrow \mathrm{H}}$} & $c$ & & & 0.01 & 0.05 \\
\hline & $\boldsymbol{y}_{\infty}$ & & & -0.10 & -0.06 \\
\hline
\end{tabular}

Note: Boldface indicates results significant at the 0.01 level and shown in Figs. 3 and 4. in small populations. First, our model includes balancing selection, which has a stabilizing effect on allele frequency. Second, $\Delta S$ did not change if we ran the model without harvesting and adjusting the degree of density dependence in juveniles such that the average population size $\approx 100$ (results not shown). Third, random genetic drift would equally likely result in fixation of size or drought resistance alleles, resulting a large scatter around the zero line in Fig. $3 \mathrm{~A}$ and B. In contrast, in our simulations $\Delta S$ significantly decreases with increasing harvesting rate and increasing degree of size selectivity. Finally, the sensitivity analysis is based on the median of 20 replicate runs at each parameter combination. Genetic drift would lead to random variation around the median response, but it should be equally 

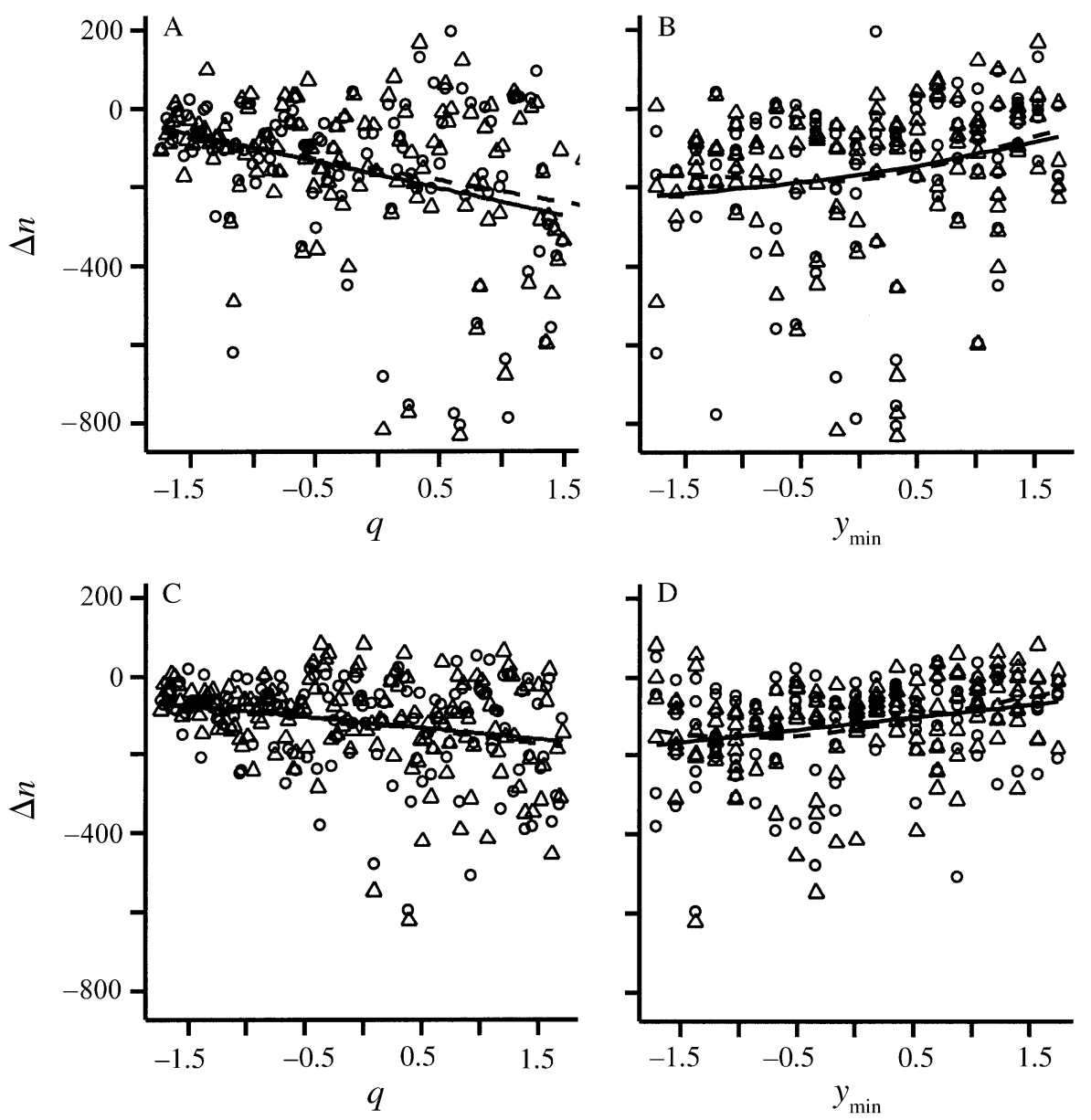

FIG. 4. Effect of size-selective harvesting on the median change in abundance $(\Delta n)$ between the onset of harvesting and 100 years later. All symbols and lines are as in Fig. 3.

likely to be in either direction, and therefore the median should be a good representation of how the model is responding to changes in parameters despite random drift in genetics and demographic stochasticity in abundance.

Hale (2001) examined the genetic diversity of red kangaroos and wallaroos (Macropus robustus) by analyzing allozymes and microsatellite loci. He did not find any significant differences in levels of allelic diversity between nonharvested and harvested areas. In his analysis he included samples from areas with harvesting rates close to $30 \%$. These results might lead to the conclusion that size-selective harvesting is not affecting allele frequencies in kangaroos. Our model highlights two alternative explanations for Hale's (2001) findings:

1) Currently the size of the nonharvested area and the dispersal rate between harvested and nonharvested populations are sufficiently large to counteract the effect of size-selective harvesting. This situation may change. There is a movement to promote kangaroo products (Grigg 1988, 1997, Grigg et al. 1995, Switala
1995, Grigg and Pople 2001), which might result in a decreasing refuge area. A large percentage of the kangaroo population is not harvested because they live in areas where harvesting it is not economical because of poor accessibility (remoteness, difficult terrain, thick vegetation, or poor road network). Ron Hacker (unpublished manuscript) estimates that currently in New South Wales $\geq 5 \%$ of the kangaroo population lives in such "economical harvest refuges," in addition to $3 \%$ that live in national parks.

2) Our model suggests that the allele frequency changes gradually. Consequently, effects on wild populations will be detectable only over a long time. It could be that the populations have not been exposed to sufficient harvesting pressure long enough to generate any measurable change in the gene frequency. Few estimates are available prior to 1980 , so the historical harvest rate that was imposed is unclear. Since 1980, the harvest rate has generally increased nationally in Australia (Grigg and Pople 2001). However, substantial harvest rates of kangaroos comparable to 
recent years have only been reported for some states (Pople and Grigg 1998).

Our model is tailored to the biology of kangaroo populations, but we believe that the value of harvest refuges demonstrated in our model would hold for a wide range of species that have to cope with a highly stochastic food supply and that experience size-selective harvesting. The advantage of constructing a species-specific model is that we know a great deal about the population processes in the model and our parameter estimates are based on empirical studies. This is particularly important because of the large uncertainty involved in modeling the genetics. The underlying genetics determining body size and the interactions with other traits are largely unknown. We now discuss the different aspects of this uncertainty.

Heritability of body size.-Heritability is the proportion of phenotypic variation due to the additive effect of genes. There is an additive genetic component to size variation (Gjedrem 1983, 1986). Roff (2000) reviewed the heritability of size at maturity for a variety of species and reported values as low as 0.09 to as high as 0.90 . The heritability of body size in natural fish populations is likely to be in the range of $0.2-0.3$ (Stokes and Law 2000). Most studies on heritability of body size are concerned with size at maturity. In our model, size at maturity is determined by Eq. 3. What changes is how quickly individuals reach a particular size. The overall heritability of growth rate to maturity (0.14) created by our genetic model is comparable, albeit at the low end of the range, with that observed in natural populations. If the heritability is excessively large, the model is overestimating the response to selective harvesting, whereas if it is too small, the model is underestimating the response. Unfortunately no information exists on the heritability of size for kangaroos.

Growth model.-A common assumption in life history models is that all individuals follow more or less the same growth trajectory (Roff 1992, 2000, Klingenberg and Spence 1997). In this case, differences in adult size are caused by different birth sizes or variation in developmental time. Alternatively, evolution could act on selecting for different intrinsic growth rates (Arendt 1997). For most species, including kangaroos, we do not know which is more important. In our model we mimic both life history tactics by assuming that the number of size genes determines either the asymptotic size or the growth rate. The sensitivity analysis of our model suggests that the way in which genes control growth does not strongly influence the selection for smaller body size due to size-selective harvesting.

Genetic trade-off.-Life history theory is based on the hypothesis that evolution is constrained by the presence of trade-offs among some of the traits that contribute to fitness (Roff 1992, Stearns 1992). One commonly assumed trade-off is that between size and survival, with the fitness trade-off arising from a corre- lation between fecundity and body size. In kangaroos, larger body size decreases age at maturity (Dawson 1995) and increases male mating success because larger males are more successful in competing for females (Moss 1995, Walker 1995).

In our model we assume that size is traded off with survival under drought conditions. We consider annual rainfall as an indicator of food and water availability, which in our model influences growth, reproduction (via juvenile survival), and adult survival. We used drought resistance as a trade-off, rather than the agedependent survival probability, for two reasons.

First, Tenhumberg et al. (2000) found that optimal life history strategies depend on whether individuals have a constant or stochastically varying food supply. Thus, kangaroos and other animals living in arid environments with a highly stochastic food supply are likely to have evolved appropriate life history strategies. By using drought resistance as a trade-off, we examined the effect of this stochastic selection pressure on the genetic response to size-selective harvesting. One alternative would be to allow the age-dependent survival probability to respond to genetic variation. This would disadvantage "large" individuals every year independent of the environmental conditions, resulting in a much stronger selection pressure for being small, and a more rapid evolutionary response to selective harvesting. Using an alternative trade-off would not alter our qualitative conclusions, because the aim of our model is not to make quantitative predictions about genetic change, but to evaluate the potential of harvest refuges as a management strategy to minimize the risk and amount of change in the allele frequency.

Second, Arendt (1997) and Reznick et al. (2000) review empirical evidence that, in a great many species, the cost of rapid growth is a reduced ability to respond to environmental stress, such as nutrient stress. Examples of stress-tolerant, relatively slow-growing species include lizards, frogs, snails, insects, and birds. Slow growth allows organisms that experience nutrient stress to use what nutrients are available most efficiently and to survive longer. In kangaroos, drought reduces the availability of water and food, resulting in increased mortality. Starving kangaroos are also particularly susceptible to hypothermia. Stress-resistant kangaroos might use nutrients to build a heavy fur or to develop greater fat reserves in favor of rapid growth. A range of possible physiological and behavioral differences is possible.

\section{Conclusions}

This study suggests that size-selective harvesting can result in smaller kangaroos of a given age with higher survival probability under drought conditions. The effect of size-selective harvesting increases with increasing harvesting rate and minimum size of the harvested animals. In scenarios with moderate dispersal from a 
nonharvested population, virtually all effects of harvesting on genetic structure disappear.

This paper highlights a potential conflict in sustainable use of wild life populations. Restricting harvesting to individuals with a high minimum size is commonly done to ensure the viability of a population. As a side effect, the balance of natural section changes to favor individuals with slower growth. Genetic change does not necessarily reduce the viability of a population. In the eyes of some kangaroo harvesters or conservation biologists, it would be beneficial to change the balance in favor of kangaroos with higher drought resistance because this would decrease the variance in the population dynamics of kangaroos. However, in a multitrait system, both positive and negative correlations can occur despite underlying physiological trade-off between pairs of traits (Charlesworth 1980, Charnov 1989). For example, Stokes and Law (2000) argue that genetic changes caused by size-selective harvesting in fish are large enough to affect the productivity of fisheries.

Because it is likely that there will be complex interactions between traits not considered in this paper, a precautionary management approach would be to minimize any genetic change, especially if we do not know that cessation of harvesting will reverse selection back to the original state (Stokes and Law 2000). Our model suggests that setting aside harvest refuges as a management strategy has a great potential to resolve this conflict. In order to determine the appropriate size and distribution of harvest refuges in the landscape, we need a better understanding of dispersal in the species in question, and the strength of selection under different harvesting regimes (i.e., different combinations of dispersal rates and degrees of size selectivity).

\section{ACKNOWLEDGMENTS}

We thank the Murray Darling Basing commission for funding this project. The manuscript was greatly improved thanks to comments from Steve McLeod, Ron Hacker, and members of the Ecology Center, University of Queensland, especially Hamish McCallum and Peter Hale. Discussions with Rob Toonen, University of Hawaii, cleaned up the description of the genetic architecture of the model. We also thank two anonymous reviewers for their useful comments. This is a contribution of the University of Nebraska Agricultural Research Division, Lincoln, Nebraska 68583, Journal Series Number 14372 .

\section{Literature Cited}

Arendt, J. D. 1997. Adaptive intrinsic growth rate: an integration across taxa. Quaterly Review of Biology 72:149177.

Armbruster, P., and R. Lande. 1993. A population viability analysis for African elephant (Loxodonta africana) - how big should reserves be? Conservation Biology 7:602-610.

Bailey, P. T. 1971. The red kangaroo, Megaleia rufa (Desmarest), in north-western New South Wales. I. Movements. CSIRO Wildlife Research 16:11-28.

Bayliss, P. 1985. The population dynamics of red and western grey kangaroos in arid New South Wales, Australia. 1. Population trends and rainfall. Journal of Animal Ecology 54: $111-125$.
Bayliss, P. 1987. Kangaroo dynamics. Pages $119-134$ in G. Caughley, N. Shepherd, and J. Short, editors. Kangaroos: their ecology and management in the sheep rangelands of Australia. Cambridge University Press, Cambridge, UK.

Blower, S. M., and H. Dowlatabadi. 1994. Sensitivity and uncertainty analysis of complex models of disease transmission: an HIV model, as an example. International Statistical Review 62:229-243.

Bürger, R. 1999. Evolution of genetic variability and the advantage of sex and recombination in changing environments. Genetics 153:1055-1069.

Cairns, S. C. 1989. Models of macropodid populations. Pages 695-704 in G. C. Grigg, P. Jarman, and I. Hume, editors. Kangaroos, wallabies and rat-kangaroos. Surrey Beatty and Sons, Sydney, New South Wales, Australia.

Cairns, S. C., and G. C. Grigg. 1993. Population dynamics of Red Kangaroos (Macropus-rufus) in relation to rainfall in the South Australian pastoral zone. Journal of Applied Ecology 30:444-458.

Carr, M. H., and D. C. Reed. 1993. Conceptual issues relevant to marine harvest refuges: examples from temperate reef fishes. Canadian Journal of Fisheries and Aquatic Sciences 50:2019-2028.

Caughley, J., P. Bayliss, and J. Giles. 1984. Trends in kangaroo numbers in western New South Wales and their relation to rainfall. Australian Wildlife Research 11:415-422.

Chapman, K. L., M. J. Lawes, and M. M. Macleod. 1998. Evaluation of non-lethal control methods on problematic samango monkeys in the Cape Vidal Recreation Reserve, greater St. Lucia Wetland Park. South African Journal of Wildlife Research 28:89-99.

Charlesworth, B. 1980. Evolution in age structured populations. Cambridge University Press, Cambridge, UK.

Charnov, E. L. 1989. Phenotypic evolution under Fisher's fundamental theorem of natural selection. Heredity 62:97106.

Clutton-Brock, T. H., F. E. Guinness, and S. D. Albon. 1982. Red deer: behaviour and ecology of two sexes. Edinburgh University Press, Edinburgh, Scotland, UK.

Conover, D. O., and S. B. Munch. 2002. Sustaining fisheries yields over evolutionary time scales. Science 297:94-96.

Croft, D. 1980. Behaviour of red kangaroos, Macropus rufus (Desmarest 1822), in north-western NSW, Australia. Australian Mammalogy 4:5-58.

Croft, D. 1999. When big is beautiful: some consequences of bias in kangaroo culling. Pages $70-73$ in M. Wilson, editor. The kangaroo betrayed. Hill of Content Publishing, Melbourne, Australia.

Croft, D. B. 1991. Home range of the euro, Macropus robustus erubescens. Journal of Arid Environments 20:99111.

Dawson, T. J. 1995. Kangaroos: the biology of the largest marsupials. University of New South Wales Press, Sydney, New South Wales, Australia.

Denny, M. J. S. 1980. Red kangaroo arid zone studies. Australian National Parks and Wildlife Service, Canberra, Australian Capital Territories, Australia.

Dias, P. C. 1996. Sources and sinks in population biology. Trends in Ecology and Evolution 8:326-330.

Donovan, T. M., R. H. Lamberson, A. Kimber, F. R. Thompson, and J. Faaborg. 1995. Modelling the effects of habitat fragmentation on source and sink demography of neotropical migrant birds. Conservation Biology 9:1396-1407.

Ealey, E. H. M. 1967. Ecology of the euro, Macropus robustus (Gould), in north-western Australia. IV. Age and growth. CSIRO Wildlife Research 12:67-80.

Edley, M. T., and R. Law. 1988. Evolution of life histories and yields in experimental populations of Daphnia magna. Biological Journal of the Linnean Society 34:309-326. 
Falconer, D. S., and T. F. C. Mackay. 1996. Introduction to quantitative genetics. Fourth edition. Longman Group, Essex, UK.

Fretwell, S. D., and H. L. Lucas. 1970. On territorial behaviour and other factors influencing habitat distribution in birds. I. Theoretical development. Acta Biotheoretica 19: $16-36$.

Frith, H. J. 1964. Mobility of the red kangaroo, Megaleia rufa. CSIRO Wildlife Research 9:1-19.

Frith, H. J., and G. Sharman. 1964. Breeding in wild populations of the red kangaroo, Megaleia rufa. CSIRO Wildlife Research 9:86-114.

Gaona, P., P. Ferreras, and M. Delibes. 1998. Dynamics and viability of a metapopulation of the endangered Iberian lynx (Lynx pardinus). Ecological Monographs 68:349-370.

Gillis, D. M., R. M. Peterman, and E. K. Pikitch. $1995 a$. Implications of trip regulations for high grading: a model of the behavior of fishermen. Canadian Journal of Fisheries and Aquatic Sciences 52:402-415.

Gillis, D. M., E. K. Pikitch, and R. M. Peterman. $1995 b$. Dynamic discarding decisions: foraging theory for highgrading in a trawl fishery. Behavioral Ecology 6:146-154.

Gjedrem, T. 1983. Genetic variation in quantitative traits and selective breeding in fish and shellfish. Aquaculture 33:5172.

Gjedrem, T. 1986. Growth and reproduction in fish and shellfish. Aquaculture 57:37-55.

Grigg, G. C. 1988. Kangaroo harvesting and the conservation of the sheep rangelands. Australian Zoologist 24:124-128.

Grigg, G. C. 1997. A crossroads in kangaroo politics. Australian Biologist 10:12-22.

Grigg, G. C., P. Hale, and D. Lunney. 1995. Conservation through sustainable use of wildlife. Centre of Conservation Biology, University of Queensland, Brisbane, Australia.

Grigg, G. C., and A. R. Pople. 2001. Sustainable use and pest control in conservation: kangaroos as a case study. Pages 403-423 in J. O. Reynolds, G. M. Mace, K. H. Redford, and J. G. Robinson, editors. Conservation of exploited species. Cambridge University Press, Cambridge, UK.

Grimm, V. 1999. Ten years of individual-based modelling in ecology: what have we learned and what could we learn in the future? Ecological Modelling 115:129-148.

Grimm, V., T. Wyszomirski, D. Aikman, and J. Uchmanski. 1999. Individual-based modelling and ecological theory: synthesis of a workshop. Ecological Modelling 115:275282.

Hale, P. 2001. Kangaroo genetics: impacts of harvesting. Report for National Parks and Wildlife Service, New South Wales University of Queensland, Brisbane, Australia.

Handfort, P., G. Bell, and T. Reimchen. 1977. A gillnet fishery considered as an experiment in artificial selection. Journal of the Fisheries Research Board of Canada 34:954-961.

Hartl, D. L., and A. G. Clark. 1989. Principles of population genetics. Second edition. Sinauer Associates, Sunderland, Massachusetts, USA.

Hundertmark, K. J., T. H. Thelen, and C. C. Schwarz. 1993. Population and genetic effects of selective harvest strategies in moose: a modeling approach. ALCES 29:225-234.

Hutchings, J. A. 1999. Influence of growth and survival costs of reproduction on the Atlantic cod, Gadus morhua, population growth rate. Canadian Journal of Fisheries and Aquatic Sciences 56:1612-1623.

Jachmann, H., P. S. M. Berry, and H. Imae. 1995. Tusklessness in African elephants: a future trend. African Journal of Ecology 33:230-235.

Jarman, P. J., and G. Coulson. 1989. Dynamics and adaptiveness of grouping in macropods. Pages 527-547 in G. C. Grigg, P. J. Jarman, and I. Hume, editors. Kangaroos, wallabies and rat-kangaroos. Surrey Beatty and Sons, Sydney, Australia.
Johnson, C. N., and P. J. Jarman. 1983. Geographical variation in offspring sex ratios in kangaroos. Search 14:152154.

Klingenberg, C. P., and J. R. Spence. 1997. On the role of body size for life-history evolution. Ecological Entomology 22:55-68.

Koojiman, S. A. L. M. 1993. Dynamic energy budgets in biological systems. Cambridge University Press, Cambridge, UK.

Lande, R. 1976. Natural selection and and random genetic drift in phenotypic evolution. Evolution 30:314-334.

Law, R. 1991. On the quantitative genetics of correlated characters under directional selection in age-structured populations. Philosophical Transactions of the Royal Society of London B 331:213-223.

Law, R., and C. A. Rowell. 1993. Cohort-structured populations, selection responses, and exploitation of the North Sea cod. Pages 155-173 in K. Stokes, J. M. McGlade, and R. Law, editors. The exploitation of evolving resources. Springer-Verlag, Berlin, Germany.

Maynard Smith, J. 1980. A new theory of sexual investment. Behavioural Ecology and Socbiology 7:247-251.

McCallum, H. 1995. Modelling translocation strategies for the bridled nailtail wallaby (Onychogalea fraenata Gould 1840): effects of reintroduction size. Pages 7-14 in M. Serena, editor. Reintroduction biology. Surrey Beatty, Sydney, Australia.

McCallum, H., editor. 2000. Population parameters. Blackwell Science, London, UK.

McCarthy, M. A. 1996. Red kangaroo (Macropus rufus) dynamics: effects of rainfall, density dependence, harvesting and environmental stochasticity. Journal of Applied Ecology 33:45-53.

Miller, R. B. 1957. Have the genetic pattern of fishes been altered by introductions or by selective fishing? Journal of the Fisheries Research Board of Canada 14:797-806.

Moss, G. L. 1995. Home range, grouping patterns and the mating system of the red kangaroo in the arid zone. University of New South Wales, Press, Sydney, Australia.

Murphy, E. J., P. G. Rodhouse, and C. P. Nolan. 1994. Modeling the selective effects of fishing on reproductive potential and population structure of squid. ICES (International Council for the Exploration of the Sea). Journal of Marine Sciences 51:299-313.

Nelson, K., and M. Soulé. 1987. Genetic conservation of exploited fishes. Pages 345-368 in N. Ryman and F. Utter, editors. Population genetics and fishery management. University of Washington Press, Seattle, Washington, USA.

Newsome, A. E. 1965. Reproduction in natural populations of the red kangaroo, Megaleia rufa (Desmarest), in central Australia. Australian Journal of Zoology 13:735-759.

Norbury, G. L., D. C. Norbury, and A. J. Oliver. 1994. Facultative behaviour in unpredictable environments: mobility of red kangaroos in arid Western Australia. Journal of Animal Ecology 63:410-418.

Policansky, D. 1993. Fishing as a cause of evolution in fishes. Pages 2-18 in K. Stokes, J. M. McGlade, and R. Law, editors. The evolution of evolving resources. Springer-Verlag, Berlin, Germany.

Pople, A. R. 1996. Effects of harvesting upon the demography of red kangaroos in western Queensland. Dissertation. University of Queensland, Brisbane, Australia.

Pople, A. R., and G. C. Grigg. 1998. Commercial harvesting of kangaroos in Australia, Unpublished document prepared for Environment Australia. University of Queensland, Brisbane, Australia.

Priddel, D. 1987. The mobility and habitat utilisation of kangaroos. Pages 100-118 in G. Caughley, N. Shepherd, and J. Short, editors. Kangaroos: their ecology and management 
in sheep rangelands of Australia. Cambridge University Press, Cambridge, UK.

Priddel, D., N. Shepherd, and G. Wellard. 1988a. Home ranges of sympatric red kangaroos, Macropus rufus, and western grey kangaroos, M. fuliginosus, in western New South Wales. Australian Wildlife Research 15:405-411.

Priddel, D., G. Wellard, and N. Shepherd. 1988b. Movements of sympatric red kangaroos, Macropus rufus, and western grey kangaroos, M. fuliginosus, in western New South Wales. Australian Wildlife Research 15:339-346.

Quinn, J. F., S. R. Wing, and L. W. Botsford. 1993. Harvest refugia in marine invertebrate fisheries: models and applications to the red sea urchin, Strongylocentrotus franciscannus. American Zoologist 33:537-550.

Ratner, S., and R. Lande. 2001. Demographic and evolutionary responses to selective harvesting in populations with discrete generations. Ecology 82:3093-3104.

Reeve, J. P. 2000. Predicting long-term response to selection. Genetical Research 75:83-94.

Reznick, D., L. Nunney, and A. Tessier. 2000. Big houses, big cars, superfleas and costs of reproduction. Trends in Ecology and Evolution 15:421-425.

Ricker, W. E. 1981. Change in the average size and average age of Pacific salmon. Canadian Journal of Fisheries and Aquatic Sciences 38:1636-1956.

Rijnsdorp, A. D. 1993. Fisheries as large-scale experiment on life history evolution: disentangeling phenotypic and genetic effects in changes in maturation and reproduction of North Sea plaice, Pleuronectes platessa L. Oecologia 96:391-401.

Roff, D. A. 1992. The evolution of life histories: theory and analysis. Chapman and Hall, New York, New York, USA.

Roff, D. A. 2000. Trade-offs between growth and reproduction: an analysis of the quantitative genetic evidence. Journal of Evolutionary Biology 13:434-445.

Rushton, S. P., G. W. Barreto, R. M. Cormack, D. W. Macdonald, and R. Fuller. 2000a. Modelling the effects of mink and habitat fragmentation on the water vole. Journal of Applied Ecology 37:475-490.

Rushton, S. P., P. W. W. Lurz, J. Gurnell, and R. Fuller. $2000 b$. Modelling the spatial dynamics of parapoxvirus disease in red and grey squirrels: a possible cause of the decline in the red squirrel in the UK? Journal of Applied Ecology 37: 997-1012.

Shepherd, N. 1987. Condition and recruitment of kangaroos. Pages 135-158 in G. Caughley, N. Shepherd, and J. Short, editors. Kangaroos: their ecology and management in the sheep rangelands of Australia. Cambridge University Press, Cambridge, UK.

Stearns, S. C. 1992. The evolution of life histories. Oxford University Press, New York, New York, USA.

Stokes, K., and R. Law. 2000. Fishing as an evolutionary force. Marine Ecology-Progress Series 208:307-309.

Stuart-Dick, R. I., and K. B. Higginbottom. 1989. Strategies of parental investment in Macropodoids. Pages 571- 592 in G. C. Grigg, P. Jarman, and I. Hume, editors. Kangaroos, wallabies and rat-kangaroos. Surrey Beatty and Sons, Sydney, Australia.

Sukumar, R. 1991. The management of large mammals in relation to male strategies and conflict with people. Biological Conservation 55:93-102.

Switala, J. 1995. The potential supply and value of kangaroo meat. Pages 237-242 in G. C. Grigg, P. Hale, and D. Lunney, editors. Conservation through sustainable use of wildlife. Centre of Conservation Biology, University of Queensland Press, Brisbane, Australia.

Tenhumberg, B., A. J. Tyre, and B. D. Roitberg. 2000. Stochastic variation in food availability influences weight and age at maturity. Journal of Theoretical Biology 202:257272.

Thelen, T. H. 1991. Effects of harvest on antlers of simulated populations of elk. Journal of Wildlife Management 55: 243-249.

Trexler, J. C., and J. Travis. 2000. Can marine protected areas restore and conserve stock attributes of reef fishes? Bulletin of Marine Science 33:853-873.

Treydte, A. C., J. B. Williams, E. Bedin, S. Ostrowski, P. J. Seddon, E. A. Marschall, T. A. Waite, and K. Ismail. 2001. In search of the optimal management strategy for Arabian oryx. Animal Conservation 4:239-249.

Trivers, R. L., and D. E. Willard. 1972. Natural selection of parental ability to vary the sex ratio of offspring. Science 179:90-92.

Walker, L. V. 1995. Mate choice in female eastern grey kangaroos Macropus giganteus. University of New England, Armidale, New South Wales, Australia.

Wohlfarth, G. W. 1986. Decline in natural fisheries: a genetic analysis and suggestion for recovery. Canadian Journal of Fisheries and Aquatic Sciences 43:1298-1306.

Wootton, J. T., and D. A. Bell. 1992. A metapopulation model of the Peregrine Falcon in California: viability and management strategies. Ecological Applications 2:307-321.

\section{APPENDIX A}

Equations, regression tables, and graphs of parameter estimation for kangaroo maturity, mortality, and growth are available in ESA's Electronic Data Archive: Ecological Archives E085-056-A1.

\section{APPENDIX B} A2.

A graph of kangaroo survival probabilities is available in ESA's Electronic Data Archive: Ecological Archives E085-056-

\section{APPENDIX C}

A model and graph of the genetics of drought resistance are available in ESA's Electronic Data Archive: Ecological Archives E085-056-A3.

\section{APPENDIX D}

A discussion of sensitivity analysis is available in ESA's Electronic Data Archive: Ecological Archives E085-056-A4. 


\section{Ecological Archives E085-056-A1}

\section{Brigitte Tenhumberg, Andrew J. Tyre, Anthony R. Pople, and Hugh P. Possingham. 2004. Do harvest refuges buffer kangaroos against evolutionary responses to selective harvesting. Ecology 85:2003-2017.}

Appendix A. Parameter estimation.

We employed logistic and nonlinear regression methods to estimate the following parameters: (1) The probability that a female sub-adult reaches maturity at any given time step (see Eq. 2 [in article], and Table A1), (2) The probability to die as a function of rainfall (see Eq. 7 [in article]), and (3) The von Bertalanffy growth equation (see Eq.10 [in article], Table A2, and Fig. A1).

For all other parameters we made educated guesses based on literature and expert advice. The consequences of the uncertainty in all parameter estimations are examined within the sensitivity analysis.

The logistic regression for maturity in females was based on annual rainfall at Currawinya National Park in southwestern Queensland. The Menindee rainfall, $R$, was converted to an equivalent amount at Currawinya using the formula

$$
R_{C W}=\frac{\left(R_{M}-\bar{R}_{M}\right)}{\sigma_{M}} \sigma_{C W}+\bar{R}_{C W}
$$

$\bar{R}$ and $\sigma$ are the average and standard deviation of annual rainfall at Menindee (M) and Currawinya (CW). This conversion assumes that there are regional differences in the responses of kangaroo populations to rainfall, presumably reflecting differences in soil and plant communities (Cairns 1989).

Juvenile mortality is generally higher and more variable than adult mortality in red kangaroo populations (Frith and Sharman 1964, Newsome 1977, Shepherd 1987, Pople 1996), and mortality of male red kangaroos is generally higher than that of females, particularly during drought (Robertson 1986, Pople 1996). To reflect these qualitative observations we arbitrarily set the minimum mortality of adult kangaroos to 0.01 and of juveniles to 0.2 . In the model, we assume that the minimum mortality of males and females are the same, but males are affected more by droughts than females.

There is considerable evidence that the mortality of kangaroos increases with decreasing rainfall (e.g., Shepherd 1987, Pople 1996), but no data are available to estimate the relationship between red kangaroo mortality and rainfall directly. The relationship between the exponential rate of increase of red kangaroos and rainfall has been described by a number of authors (e.g., Bayliss 1987, Cairns and Grigg 1993). Bayliss (1987) developed a numerical response model relating red kangaroo rate of increase and rainfall at Kinchega National Park:

$$
r=-0.57+1.14\left(1-e^{-0.004 R}\right)
$$

where $r$ is the annual exponential rate of increase between winter aerial surveys and $R$ is the previous calendar year rainfall. The underlying mechanisms for varying $r$ are changes in survival and birth processes as described in the Euler-Lotka equation (McCallum 2000):

$$
\sum_{x=1}^{\infty} e^{-r x} m_{x} l_{x}=1
$$


where $x$ is the age of individuals, $l_{x}$ is the age-specific survivorship, $m_{x}$ is the age-specific fecundity and $r$ is the rate of increase of the population when it has a stable age distribution.

In our model we use Eq. 7 to describe the relationship between mortality and rainfall. The parameter $a_{x, z}$ in Eq. 7 is determined by $\mu_{\infty, x, z}$ and $\mu_{0, x, z}$ (see Eq. 8). We initially estimated $b_{x, z}$ from data in Pople (1996). We used the initial $b_{x, z}$ and $a_{x, z}$ in Eq. 7 to calculate $\mu_{R, x, z}$ at a range of rainfall values. We can obtain $l_{x}$ from $\mu_{R, x, z}$ because $l_{x}=l_{x-1} \mu_{R, x-1, z}$ and $l_{0}=1$. We then calculated the corresponding $r$ using (Eq. A.3). The resulting curve of $r$ as a function of rainfall was then compared with Eq. A.2. We iteratively improved our initial estimates of $b_{x, z}$, until the $r$-values corresponded to those generated by Bayliss' model. As a result of data limitations we used a stagestructured version of Eq. A.3 with $x \in$ \{adult, juvenile\}, and made the following simplifying assumptions:

1. The maximum survival rate is constant for all ages: $1-\mu_{\infty, x, z}=0.99$ for adults and $1-\mu_{\infty, x, z}=0.8$ for juveniles.

2. The fecundity is independent of age: $m_{\text {adilt }}=0.67$ (Tyndale-Biscoe and Renfree 1987).

The final estimated survival curve is shown in Fig. A2. Pople (1996) found no influence of age on fecundity in mature red kangaroos. However, droughts can induce delays in the onset of sexual maturity (Frith and Sharman 1964) and induce anoestrus (Newsome 1964). In our model, anoestrus is included indirectly as decreased juvenile survival in droughts.

At high rainfall, the $l_{x}$ and $m_{x}$ schedule used in Eq. A.3 cannot return the high $r$-values (i.e. $>r_{\max }$ ) predicted by Bayliss' model. This is almost certainly due to the unstable age distributions underlying Bayliss' data, resulting from low juvenile and adult male survival during drought (Bayliss 1985a, Pople 1996).

Table A1. Logistic regression to estimate the influence of weight, age and rainfall on the probability to mature.

\begin{tabular}{|l|l|l|l|l|}
\hline & Estimate & Std. Err. & z value & $\operatorname{Pr}(>|z|)$ \\
\hline (Intercept) & 1.13672 & 5.61169 & 0.203 & 0.83948 \\
\hline Weight & 0.65345 & 0.14089 & 4.638 & $3.52 \mathrm{e}-0.6$ \\
\hline Age & -8.29777 & 3.40324 & -2.438 & 0.01476 \\
\hline Rain & -0.04551 & 0.01601 & -2.843 & 0.00447 \\
\hline Age:Rain & 0.03277 & 0.01046 & 3.134 & 0.00172 \\
\hline
\end{tabular}

Notes: From 1991-2000 annual rainfall, weight and maturity status of 474 female kangaroos was recorded. Individuals were classified as mature if they carried a young or if their teats were enlarged (Pople, unpublished data). Null deviance $=453.32$ on 360 degrees of freedom; Residual deviance $=104.92$ on 356 degrees of freedom. The age and rainfall coefficients are both negative because the positive effects they both have on the probability a female is mature are incorporated into the interaction term.

Table A2. Nonlinear regression to estimate Bertalanffy growth parameters.

\begin{tabular}{|c|c|c|c|c|c|c|c|}
\hline & & \multicolumn{3}{|c|}{ Males } & \multicolumn{3}{|c|}{ Females } \\
\hline & & Estimate & Standard error & $t$ value & Estimate & Standard error & $t$ value \\
\hline
\end{tabular}




\begin{tabular}{|l|l|l|l|l|l|l|l|}
\hline Bul & $y_{\infty}$ & 184.43 & 2.236 & 82.4809 & 152.969 & 0.8506 & 179.837 \\
\hline & $c$ & 0.2613 & 0.0244 & 10.713 & 0.5402 & 0.0393 & 13.7322 \\
\hline & $x_{0}$ & -3.2515 & 0.4085 & -7.9594 & -1.3852 & 0.2193 & -6.3163 \\
\hline Mul & $y_{\infty}$ & 181.94 & 2.2875 & 79.5368 & 153.86 & 0.6952 & 221.324 \\
\hline & $c$ & 0.2554 & 0.0286 & 8.9224 & 0.4651 & 0.0374 & 12.4491 \\
\hline & $x_{0}$ & -3.2692 & 0.5344 & -6.1179 & -1.9794 & 0.3064 & -6.4592 \\
\hline $\mathrm{CW}$ & $y_{\infty}$ & 181.741 & 1.5762 & 115.304 & 152.756 & 0.5214 & 292.975 \\
\hline & $c$ & 0.2352 & 0.0196 & 11.9932 & 0.4105 & 0.0283 & 14.5005 \\
\hline & $x_{0}$ & -3.7041 & 0.4032 & -9.1863 & -2.4267 & 0.2667 & -9.0993 \\
\hline
\end{tabular}

Notes: Data were collected in 1991 at Bulgunnia in NW SA (Bul), Mulyungarie in NE SA (Mul), and Currawinya in Qld (Cw). $y_{\infty}$ is the asymptotic growth, $c$ is the growth rate and $x_{0}$ is the shift parameter. The residual standard errors, RSE, and degrees of freedom, $\mathrm{df}$, for the different locations are as follows. Bul: $\mathrm{RSE}=4.78$ on $147 \mathrm{df}$ for males, or RSE $=4.07$ on $134 \mathrm{df}$ for females; Mul: $\mathrm{RSE}=5.82$ on $92 \mathrm{df}$ for males, or RSE $=4.08$ on $149 \mathrm{df}$ for females; Cw: RSE $=6.04$ on $158 \mathrm{df}$ for males, or RSE $=$ 4.05 on $178 \mathrm{df}$ for females.

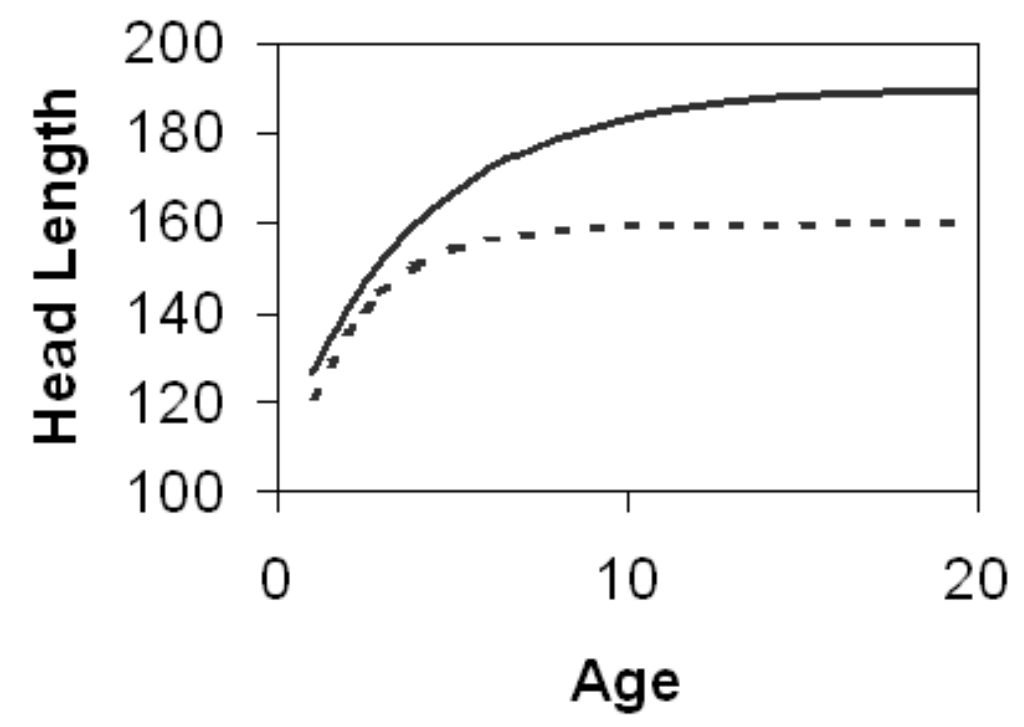

FIG. A1. Von Bertalanffy growth curves for male and female red kangaroos (see Eq.10). Parameters for males (solid line): $y_{\infty}=190, x_{0}=-3.4, c=0.25$; parameters for females (dotted line):

$y_{\infty}=160, x_{0}=-2, c=0.47$. 


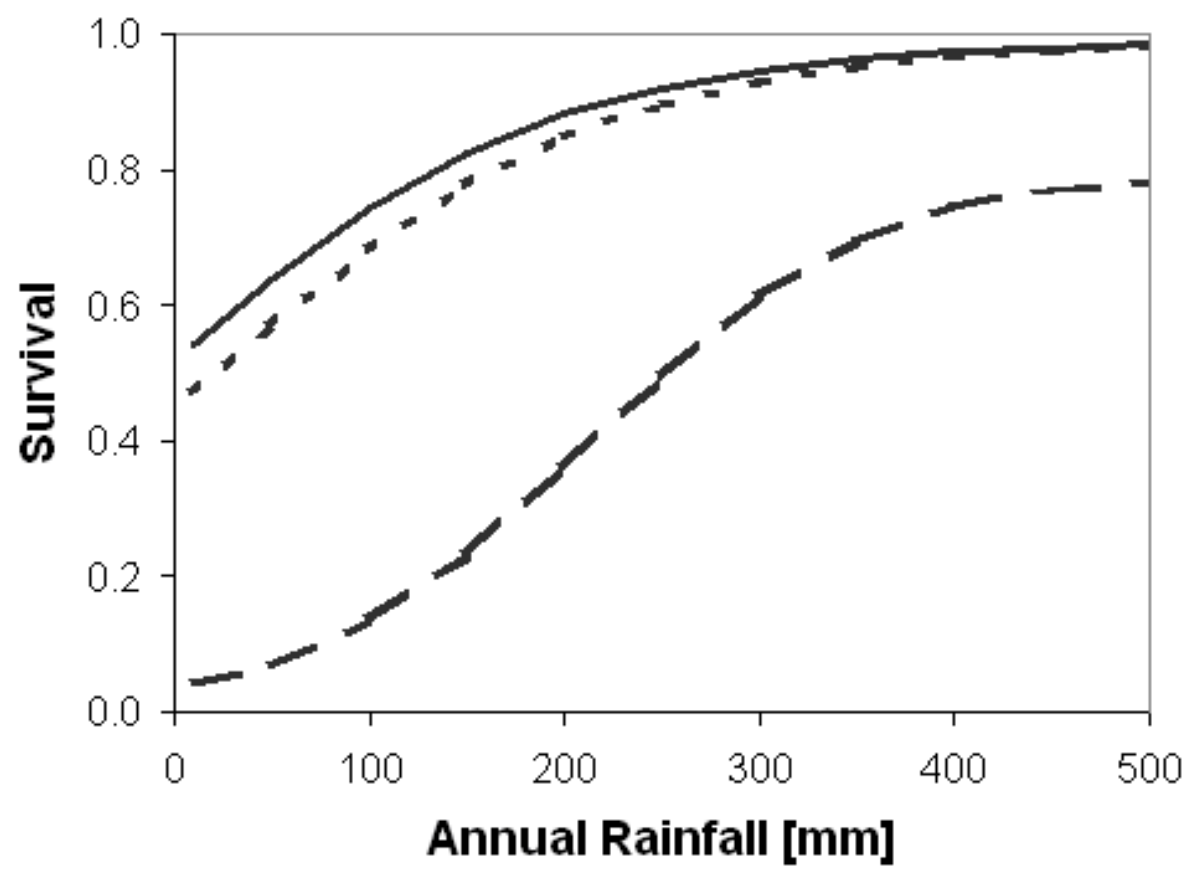

FIG. A2. Survival probability as a function of annual rainfall for adult females (solid line), adult males (dotted line), and juveniles (broken line).

\section{Literature cited}

Bayliss, P. 1985. The population dynamics of Red and Western Grey Kangaroos in arid New South Wales, Australia .2. The numerical response function. Journal of Animal Ecology 54:27-135.

Bayliss, P. 1987. Kangaroo dynamics. Pages 119-134 in G. Caughley, N. Shepherd, and S. J., editors. Kangaroos: their ecology and management in the sheep rangelands of Australia. Cambridge University Press, Cambridge, UK.

Cairns, S. C. 1989. Models of macropodid populations. Pages 695-704 in G. C. Grigg, P. Jarman, and I. Hume, editors. Kangaroos, Wallabies and Rat-kangaroos. Surrey Beatty and Sons, Sydney, Australia.

Cairns, S. C., and G. C. Grigg. 1993. Population dynamics of Red Kangaroos (Macropus-Rufus) in relation to rainfall in the South Australian pastoral zone. Journal of Applied Ecology 30:444-458.

Frith, H. J., and G. Sharman. 1964. Breeding in wild populations of the red kangaroo, Megaleia rufa. CSIRO Wildlife Research 9:86-114.

McCallum, H., editor. 2000. Population Parameters. Blackwell Science, London, UK.

Newsome, A. E. 1964. Anoestrus in the red kangaroo, Megaleia rufa (Desmarest). Australian Journal of Zoology 12:9-17.

Newsome, A. E. 1977. Imbalance in the sex ratio and age structure the red kangaroo, Macropus rufus, in central Australia. Pages 221-233 in B. Stonehouse and D. Gilmour, editors. The Biology of Marsupials. Macmillan, London, UK.

Pople, A. R. 1996. Effects of harvesting upon the demography of red kangaroos in western Queensland. PhD Dissertation. The University of Queensland, Brisbane, Australia. 
Robertson, G. G. 1986. The mortality of kangaroos in drought. Australian Wildlife Research 13:349-354.

Shepherd, N. 1987. Condition and recruitment of kangaroos. Pages 135-158 in G. Caughley, N. Shepherd, and J. Short, editors. Kangaroos: their ecology and management in the sheep rangelands of Australia. Cambridge University Press, Cambridge, UK.

Tyndale-Biscoe, C. H., and M. B. Renfree. 1987. Reproductive physiology of marsupials. Cambridge University Press, Cambridge, UK. 


\section{Ecological Archives E085-056-A2}

Brigitte Tenhumberg, Andrew J. Tyre, Anthony R. Pople, and Hugh P. Possingham. 2004. Do harvest refuges buffer Kangaroos against evolutionary responses to selective harvesting? Ecology 85:2003-2017.

Appendix B. Survival probabilities.

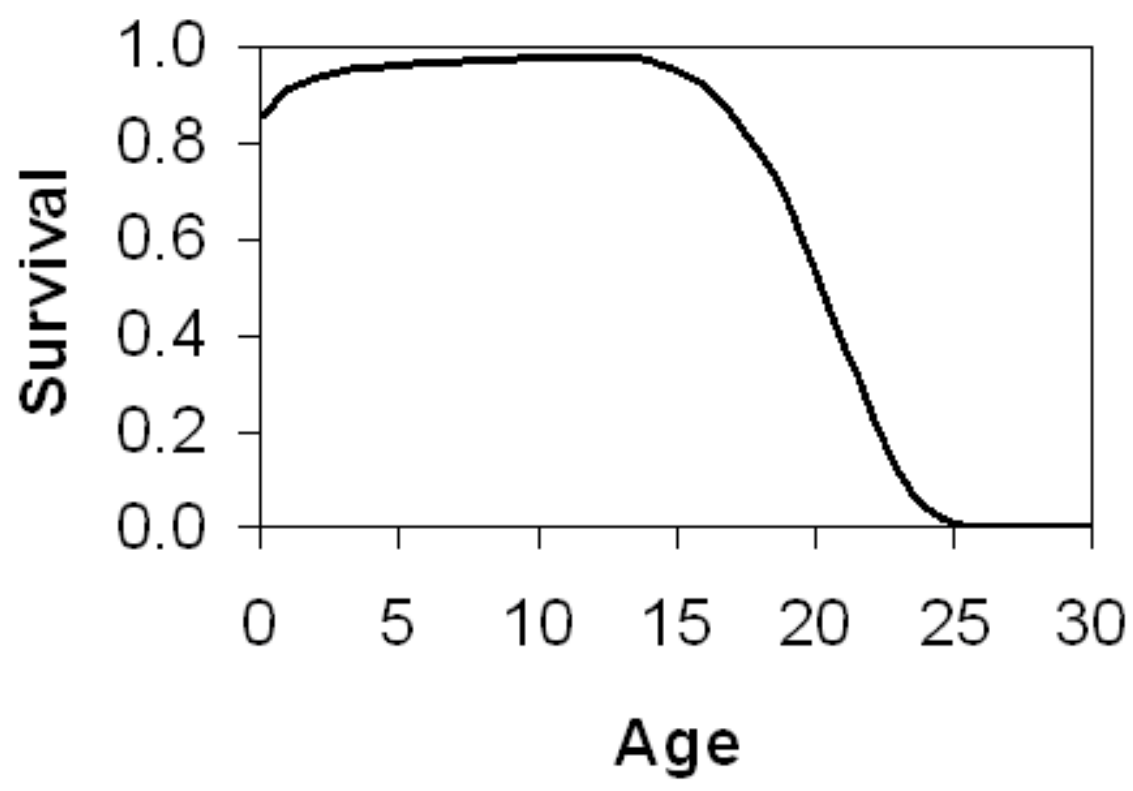

FIG. B1. Weibull curve describing the influence of age on the survival probability ( $\rho=0.05 ; \kappa=0.3$, if age $<14$ years, otherwise $\kappa=10$ ). 


\section{Ecological Archives E085-056-A3}

Brigitte Tenhumberg, Andrew J. Tyre, Anthony R. Pople, and Hugh P. Possingham. 2004. Do harvest refuges buffer Kangaroos against evolutionary responses to selective harvesting? Ecology 85:2003-2017.

Appendix C. Genetics of drought resistance.

We model the increasing influence of "drought resistance" alleles with decreasing rainfall by changing the variance as a function of rainfall $(R)$,

$$
\sigma_{\text {drought }}=m e^{-d R}
$$

where $m$ is the maximum variance and $d$ is a parameter influencing how quickly the variance increases with decreasing rainfall (Fig. C1).

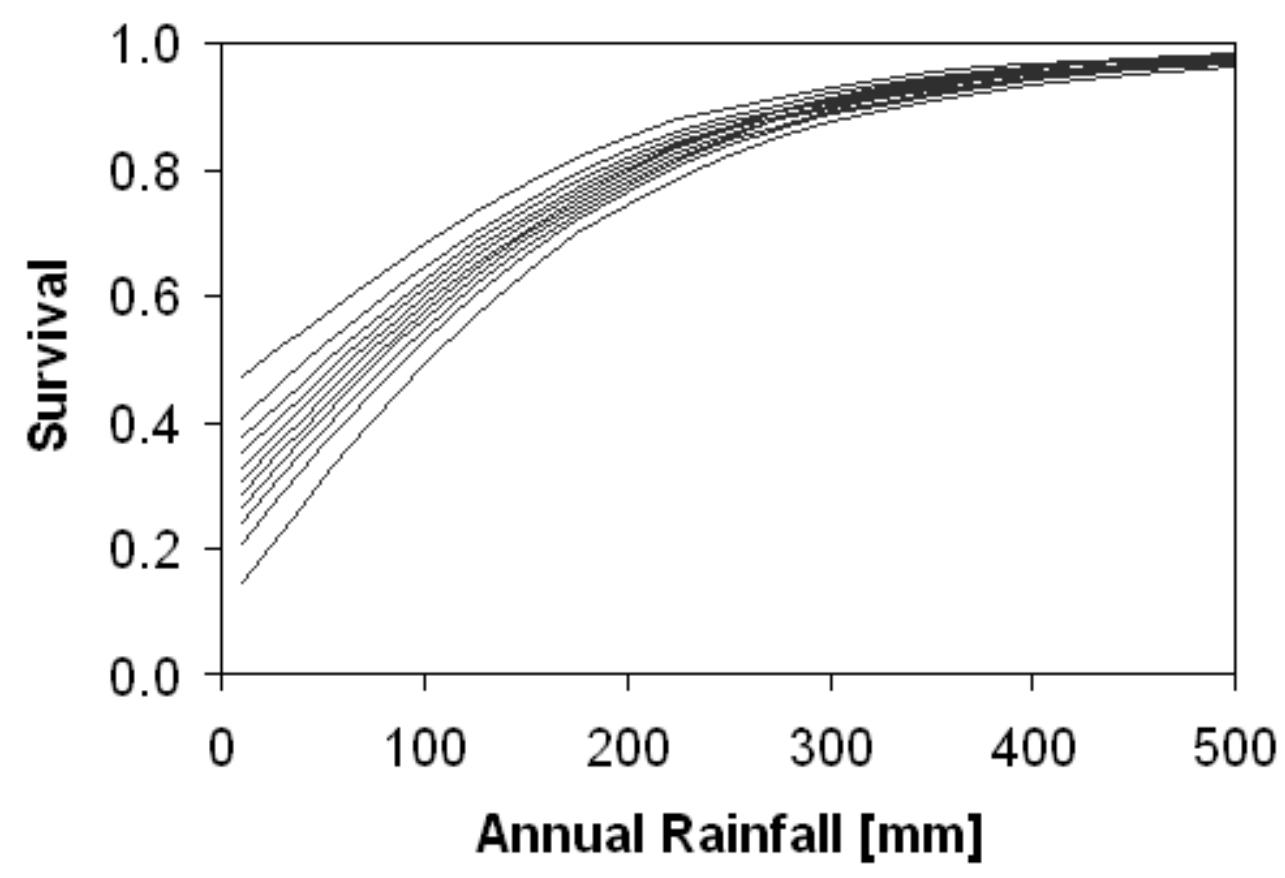

FIG. C1. Survival probability of males as a function of the frequency of drought resistance genes. The uppermost curve illustrates the survival of individuals with the maximum number of drought resistance alleles, and the lowest curve the survival of individuals with zero drought resistance alleles. 


\title{
Ecological Archives E085-056-A4
}

\section{Brigitte Tenhumberg, Andrew J. Tyre, Anthony R. Pople, and Hugh P. Possingham. 2004. Do harvest refuges buffer Kangaroos against evolutionary responses to selective harvesting? Ecology 85:2003-2017.}

\author{
Appendix D. Sensitivity Analysis.
}

Latin Hypercube Sensitivity analysis (LHS; Blower and Dowlatabadi 1994) is a type of stratified Monte Carlo sampling. It is an extremely efficient sampling design because each value of a parameter is only used once in the analysis. The estimation of uncertainty for each parameter is modeled by treating each parameter as a random variable. Probability distribution functions (pdfs) are defined for each parameter. We used normal, gamma, or beta distributions (see Table 1). For a sample size of $N$, we broke each of these distributions into $N$ intervals, each of equal probability. We then chose the midpoint of each interval and generated an LHS table as an $N \times K$ matrix, where $N$ is the number of simulations and $K$ is the number of sampled input parameters. The matrix is generated as follows: $N$ sampling indices of the first variable are paired randomly with $N$ sampling indices of the second variable, these $N$ pairs are randomly paired with the $N$ values of the third variable, and so on until all $K$ input variable are included. This $N \times K$ matrix gives $N$ sets of parameter values, which are used for simulations. The $N$ results are basis for the sensitivity conclusions. In particular, sensitivity to a given parameter is judged by partial correlation between the parameter and the simulation results. This partial rank correlation is based on ranks of the results and of the parameter values within their columns, rather than on the raw values.

An exact formula to calculate an appropriate sample size does not exist (1994), but it has been established empirically that $N>4 / 3 K$ (McKay et al. 1979). In our case $K=44$, and we simulated each of the four scenarios with 150 different parameter combinations $(N=150)$ or more than three times the suggested minimum. We repeated each parameter combination 20 times because the model is stochastic. Therefore the whole sensitivity analysis is based on 12000 simulations $(4 \times 150 \times 20)$. See Fig. D1 for more details on the LHS.

As only a few of the parameter distribution functions were normal distributions the output variable $\Delta S$ is frequently a nonlinear function of the input variables. Therefore, we normalized all input variables and then compared the relative effect of changing a parameter value one standard deviation above or below the mean value on $\Delta S$. We used a partial rank correlation coefficient (PRCC) to evaluate statistical relationships. PRCC calculates the statistical relationship between each input parameter and $\Delta S$ while keeping all other input parameters constant at their expected value (Conover 1980). This procedure enables us to determine the independent effects of each parameter, even if the parameters are correlated. We examined the monotonicity between a specific input variable and $\Delta S$ by examining scatter plots. The sign of the PRCC indicates the qualitative relationship between the input variable and $\Delta S$, and the magnitude of PRCC indicates the importance of the input variable in contributing to the imprecision in predicting the difference in the proportion of size genes, $\Delta S$. The relative importance of the input variables can be directly evaluated by comparing the PRCC values. The calculation of PRCC is described in Blower and Dowlatabadi (1994). 


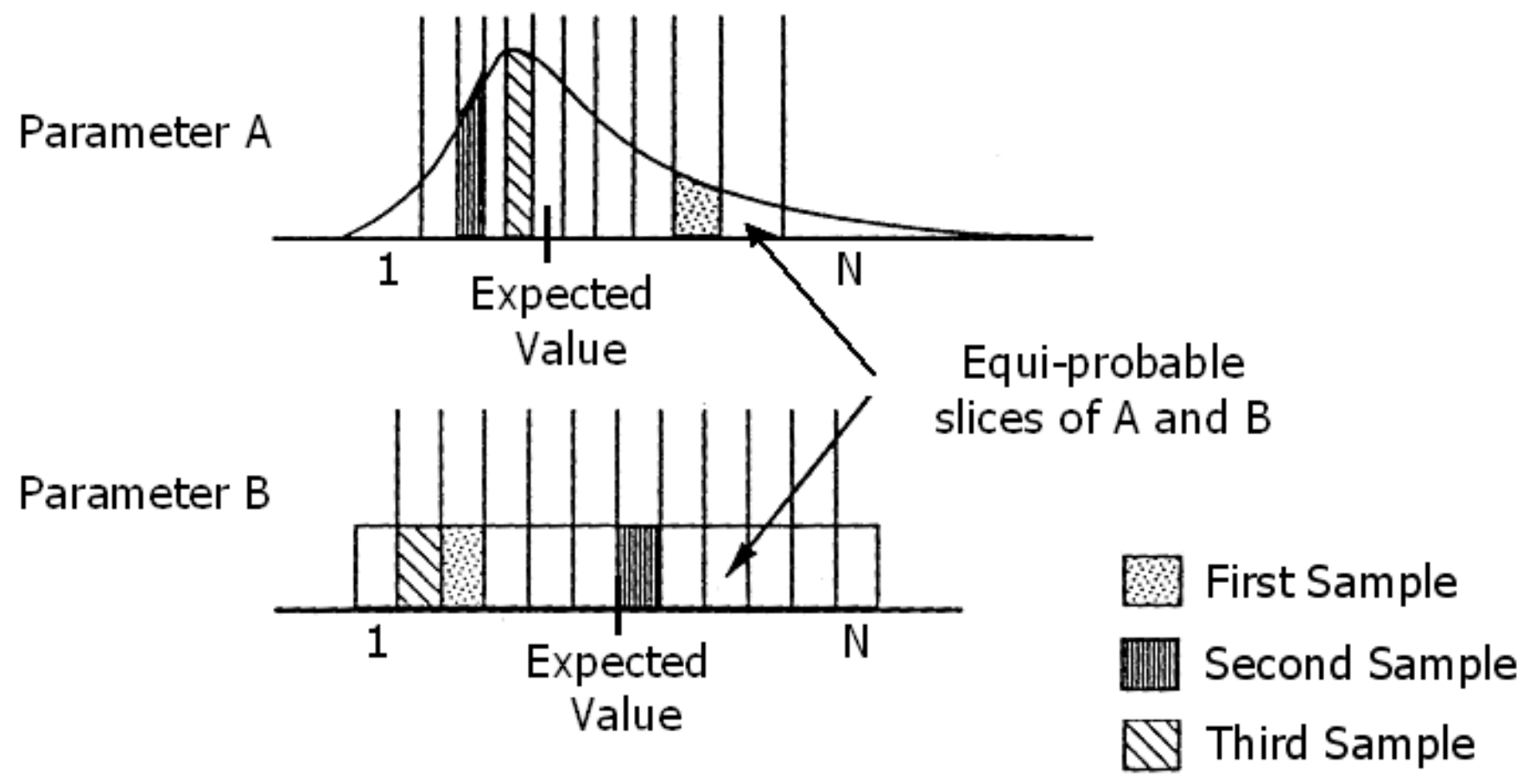

FIG. D1. Schematic Latin Hypercube Sampling technique for a hypothetical two-parameter model, modified from (Blower and Dowlatabadi 1994). Probability density functions (pdfs) of our model were divided into 150 equi-probable intervals. For each simulation a value for each parameter combination is selected from one of these intervals at random, and without replacement.

\section{Literature cited}

Blower, S. M., and H. Dowlatabadi. 1994. Sensitivity and uncertainty analysis of complex models of disease transmission: an HIV model, as an example. International Statistical Review 62:229-243.

Conover, W. J. 1980. Practical nonparametric statistics, Second edition. John Wiley and Sons, New York, New York, USA.

McKay, M. D., W. J. Conover, and R. J. Beckman. 1979. A comparison of three methods for selecting values of input variables in the analysis of output from a computer code. Technometrics 21:239-245. 